\title{
The Vulnerability of Global Cities to Climate Hazards
}

\author{
Andrew Schiller*, Alex de Sherbinin†, Wen-Hua Hsieh*, Alex Pulsipher†† \\ * George Perkins Marsh Institute, Clark University \\ † Center for International Earth Science Information Network (CIESIN), \\ Columbia University \\ †† Graduate School of Geography, Clark University
}

\begin{abstract}
Vulnerability is the degree to which a system or unit is likely to expierence harm due to exposure to perturbations or stress. The vulnerability concept emerged from the recognition that a focus on perturbations alone was insufficient for understanding responses of and impacts on the peoples, ecosystems, and places exposed to such perturbations. With vulnerability, it became clear that the ability of a system to attenuate stresses or cope with consequences constituted an important determinant of system response, and ultimately, of system impact. While vulnerability can expand our ability to understand how harm to people and ecosystems emerges and how it can be reduced, to date vulnerability itself has been conceptually hampered. It tends to address single stresses or perturbations on a system, pays inadequate attention to the full range of conditions that may render the system sensitive to perturbations or permit it to cope, accords short shrift to how exposed systems themselves may act to amplify, attenuate, or even create stresses, and does not emphasize the importance of human-environment interactions when defining the system exposed to stresses. An extended framework for vulnerability designed to meet these needs is emerging from a joint research team at Clark University, the Stockholm Environment Institute, Harvard University, and Stanford University, of which several authors on this paper are part. This paper is a first attempt to explore the utility of this extended vulnerability framework, by conducting a preliminary application of it to three global coastal cities with regard to their vulnerabilities to climate hazards. While this new framework needs further refinement and testing, and some methodological obstacles remain, our research suggests there is benefit from using the extended framework to guide assessments of vulnerability. The framework illuminated further system characteristics that, in unique combinations, create place-based vulnerabilities to climate hazards. The framework's complexity, however, required us to conduct outside the framework several analyses comparing bundles of stresses to which the systems were exposed, and system characteristics that give rise to vulnerabilities, to uncover some of the most insightful results.
\end{abstract}

\section{Introduction}

Global cities are engines of economic growth and centers of innovation for the global economy and the hinterlands of their respective nations. The foundations of prosperity and prominence for most global cities lie in their long-standing commercial relationships with the rest of the world. To facilitate trade, most global cities are located on or near the coast. They are also often located in lowlying areas near the mouths of major rivers, which served as conduits for commerce between interior agricultural and industrial regions and the rest of the world. As it happens, these locations place global cities at greater risk from current and projected climate hazards such as cyclones, high winds, flooding, coastal erosion and deposition, and sea-level rise (Nicholls 1995, Rosenzweig \& Solecki 2001).

Global cities are also important centers of population concentration and growth. According to Brockerhoff (2000), just 25 years ago less than 2 percent of the global population resided in "megacities" of 10 million or more inhabitants. Today the proportion exceeds 4 percent, and by 2015 it will top 5 percent, when megacities will likely house 400 million people. The phenomenal growth rates that most developing country megacities experienced from the 1960s to the 1980s have now tapered off somewhat, but because lower rates are being applied to higher population bases, the absolute numbers being added to their populations are still high. The fact that so many people reside in megacities near coastlines, and that these cities continue to grow, underscores the importance of assessing the vulnerability of such cities to coastal climate hazards. 
Recent incidents have highlighted the vulnerability of urban areas in general to climate hazards. Flash floods and landslides in northern Venezuela killed almost 30,000 and left another 600,000 homeless in December 1999 (Bizarro 2001). Most of these casualties were in the Caracas metropolitan area, where highly vulnerable squatter settlements perched on steep hillsides were severely affected by mudslides. In the fall and early winter of 2000 rain and gales battered much of northern Europe, which in England alone killed four people and cost over one billion pounds (\$1.4 billion) in damages. Similar storms battered northern Europe in December 1999. In France, torrential rain and high winds of 90 to 105 miles per hour closed down Charles de Gaulle and Orly airports and affected subway and commuter train service in and around Paris (NOAA/OGP 1999). Evidence suggests that global climatic change may be in part responsible for wetter winters and hotter and dryer summers in northern Europe (Collett-White 2001). In June 2001, tropical storm Allison hit Houston, Texas, flooding 20,000 homes, causing over $\$ 1$ billion in damages, and engendering some unanticipated damages, such as the flooding of the Texas Medical Center, where researchers reportedly lost up to 35,000 laboratory animals that represented years of medical trials (NOAA/OGP 2001). This, like the flooding of hog farms that contaminated waterways and increased the risk of disease outbreak in North Carolina, USA in the aftermath of Hurricane Floyd in 1999, underscores the uncertainties of climate impacts, and the need to clearly examine and prepare for chains of events that may seem highly unlikely but do occur with greater frequency than in the past, and endanger many more lives.

With recent negotiations surrounding the Kyoto Protocol of the UN Framework Convention on Climate Change, the emphasis of climate change policy has largely been on mitigation. As necessary as these efforts are, it is clear that more attention needs to be given to adaptation to the climatic changes that are already under way, and that will be exacerbated by future emissions of greenhouse gases. Rayner and Malone (1997) argue that "the record and prospects of achieving emissions reductions suggest it would be prudent to expand the repertoire of climate-change policies, if only because our past emissions and the timetable for any plausible reduction program mean climate change is already upon us." Among other elements, disaster preparedness and management plans are vital components of an adaptation strategy. But to design these, we need a better understanding of who and what are vulnerable to what kind of climate hazards, what makes them vulnerable, and where these people and systems are located.

This paper utilizes an extended framework of vulnerability emerging from the research community to assess the vulnerability of three global cities to climate hazards, with the goal of testing the value of this new framework and exploring what new insights, if any, emerge from its application. This is the first time this extended framework for vulnerability has been tested. The first section of this paper addresses the multiple ways that vulnerability is framed in the literature and describes the emerging framework for vulnerability. The following section presents results of a preliminary analysis of three global cities in the developing world, Mumbai, Rio de Janeiro, and Shanghai, and their respective vulnerabilities to climate hazards. We conclude the paper with a discussion and conclusions regarding this new and extended framework, and its potential value and shortcomings for guiding vulnerability assessments.

\section{Framing Vulnerability}

Vulnerability is the degree to which a system or unit is likely to expierence harm due to exposure to perturbations or stress. The concept of vulnerability originated in research communities examining risks and hazards, climate impacts, and resilience. The vulnerability concept emerged out of the recognition by these research communities that a focus on perturbations alone (environmental, 
socioeconomic, or technological) was insufficient for understanding responses of, and impacts on, systems (social groups, ecosystems, or places) exposed to such perturbations. With the concept of vulnerability, it became clear that the ability of a system to attenuate stresses or cope with consequences through various strategies or mechanisms constituted a key determinant of system response, and ultimately, of system impact. Clearer understanding of coping strategies or mechanisms can thus illuminate who and what are at risk from what, and how specific stresses and perturbations evolve into risks and impacts.

Vulnerability in the human sciences is typically identified in terms of three elements: (1) system exposure to crises, stresses, and shocks; (2) inadequate system capacities to cope; and (3) severe consequences and attendant risks of slow (or poor) system recovery.

This perspective from the human sciences suggests that the most vulnerable individuals, groups, classes, and regions or places (ecosystems per se are not addressed) are those that (1) experience the most exposure to perturbations or stresses, (2) are the most sensitive to perturbations or stresses (i.e., most likely to suffer from exposure), and (3) have the weakest capacity to respond and ability to recover.

Beyond this broad agreement, the human sciences apply to vulnerability various frameworks and causal structures, each of which generates different research questions and methodologies. Extending the vulnerability concept to ecological systems serves to amplify this variation.

At least two primary framing designs for vulnerability are common in the human sciences: riskhazards (RH) and pressure-and-release (PAR) (Fig. 1A \& B). Each framework is conceptual, and reduced from "models" that attempt to both identify and connect the basic elements involved in producing vulnerability. Those concerned with behavioral or decision-making resources and opportunities that can be utilized in response to stresses or perturbations most often use the RH model. Alternatively, those concerned with political or economic structures that constrain behaviors or restrict opportunities for response to stresses or perturbations frequently prefer the PAR model.

These frameworks are useful in characterizing "human vulnerability," but they mask the complexity of the components, states, and interactions that enter into a more robust construction of vulnerability, and thus they frequently provide simplistic indices and measures that may be misleading or even incorrect. In particular, these frameworks tend to address single stresses or perturbations on an exposed human system (group or place), and they pay inadequate attention to the full range of conditions that may render the system sensitive to perturbations, or permit it to cope with exposures. They do not consider carefully the role of exposed systems themselves in acting to amplify, reduce, or even create stresses. Finally, interacting or coupled human and environmental systems receive virtually no attention. 
Fig. 1A: Risk-Hazards Framework

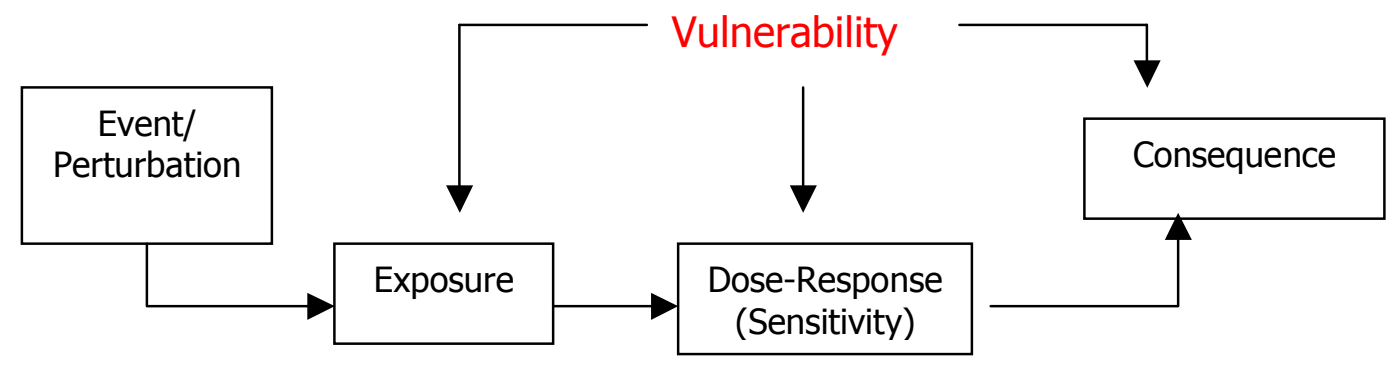

Fig. 1B: Pressure-and-Release Framework

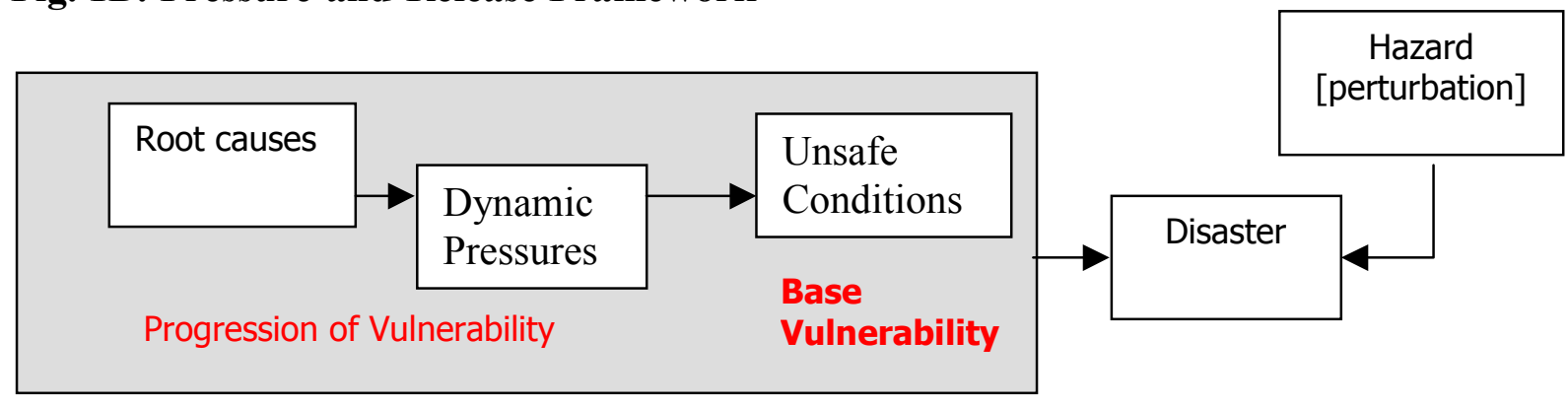

Comparisons of the uses of the term vulnerability in the human-sciences literature illustrate these limitations (Table 1). Most of the work to date treats, in a static way, a single perturbation on a social receptor (a person, household, village, or society). By contrast, sustainability science (Kates et al 2001; NRC 1999) calls for exploring different and more inclusive dimensions of vulnerability, including how it emerges and ways to reduce it. These more complex dimensions of vulnerability require a framework that takes into account multiple/sequential perturbations that relate synergistically, interacting human-environment systems, and dynamically changing coping strategies and mechanisms - elements that are not addressed jointly to date in the human-sciences literature. Figure 2 illustrates the shift in research focus from stresses to increasingly sophisticated concepts of vulnerability. 


\section{Table 1 Selected definitions of vulnerability in the human sciences}

\section{Gabor and Griffith (1980)}

Vulnerability is the threat (to hazardous materials) to which people are exposed (including chemical agents and the ecological situation of the communities and their level of emergency preparedness). Vulnerability is the risk context.

\section{Timmerman (1981)}

Vulnerability is the degree to which a system acts adversely to the occurrence of a hazardous event. The degree and quality of the adverse reaction are conditioned by a system's resilience (a measure of the system's capacity to absorb and recover from the event).

\section{UNDRO (1982)}

Vulnerability is the degree of loss to a given element or set of elements at risk resulting from the occurrence of a natural phenomenon of a given magnitude.

Susman et al. (1984)

Vulnerability is the degree to which different classes of society are differentially at risk.

\section{Bogard (1989)}

Vulnerability is operationally defined as the inability to take effective measures to insure against losses. When applied to individuals vulnerability is a consequence of the impossibility or improbability of effective mitigation and is a function of our ability to detect the hazards.

\section{Mitchell (1989)}

Vulnerability is the potential for loss.

\section{Chambers (1989)}

Vulnerability refers to exposure to contingencies and stress, and difficulty in coping with them. Vulnerability has thus two sides: an external side of risks, shocks, and stress to which an individual or household is subject: and an internal side which is defenselessness, meaning a lack of means to cope without damaging loss.

\section{Liverman (1990)}

Distinguishes between vulnerability as a biophysical condition and vulnerability as defined by political, social and economic conditions of society...vulnerability is defined both in geographic space (where vulnerable people and places are located) and in social space (who in that place is vulnerable).

\section{Downing (1991)}

Vulnerability has three connotations: it refers to a consequence (e.g., famine) rather than a cause (e.g., drought); it implies an adverse consequence; and it is a relative term that differentiates among socio-economic groups or regions, rather than an absolute measure of deprivation.

Dow (1992)

Vulnerability is the differential capacity of groups and individuals to deal with hazards based on their positions within physical and social worlds.

Watts and Bohle (1993)

Vulnerability is defined in terms of exposure, capacity and potentiality. Accordingly, the prescriptive and normative response to vulnerability is to reduce exposure, enhance coping capacity, strengthen recovery potential and bolster damage control (i.e., minimize destructive consequences) via private and public means.

Cutter et al. (2000)

Broadly defined, vulnerability is the potential for loss of property or life from environmental hazards. 
Figure 2. From defining stresses to understanding vulnerabilities (1) early work emphasized stress characterization. (2) Vulnerability broadened the idea of impact by focusing on characteristics of the exposed system that could help it resist, cope, or recover from stress. (3) Vulnerability has been limited by incomplete conceptual frames, owing to a focus on single stresses and social vulnerabilities. (4) Expanding vulnerability to include multiple interacting stresses, the notion of an exposed system as one composed of coupled humanenvironment components, and making explicit that responses of the system itself can both dampen and increase various stresses and perturbations, brings a more complete picture of vulnerability.

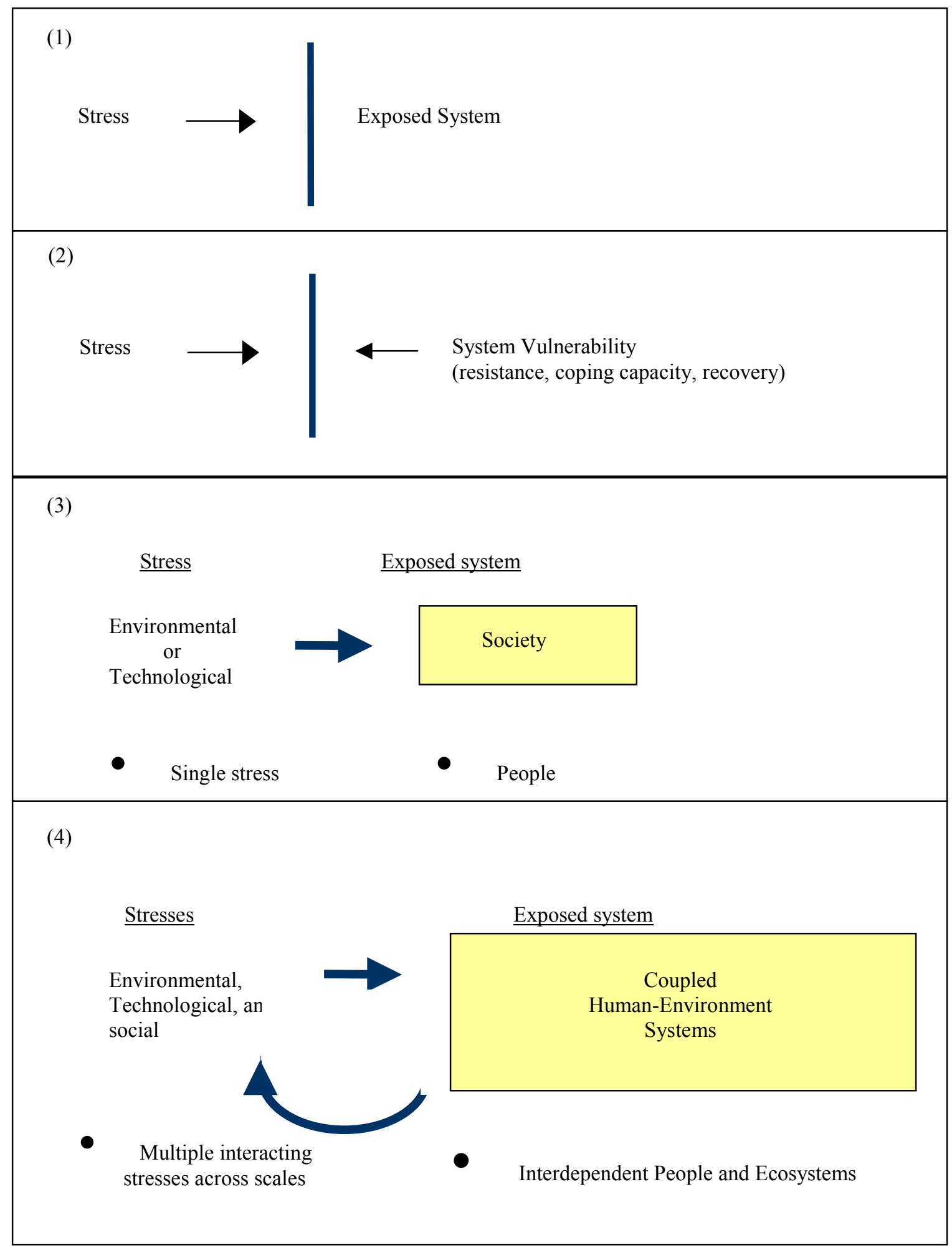


Seeking to address the above described conceptual limitations to help facilitate a better understanding of how vulnerability emerges in certain systems and what can be done about it, researchers at Clark University, the Stockholm Environment Institute, Stanford University, and Harvard University have been working to develop an extended vulnerability framework. The proposed framework addresses the vulnerability of interacting human-environment systems to multiple and synergistic stresses that emanate from within as well as outside of the system (Figure 3). The diagram in Figure 3 depicts such a dynamic system, and illustrates these feedbacks and links to forces and factors that operate both "outside" and "inside" the immediate system. Owing to the figure's complexity, it does not directly illustrate the hierarchical (spatial and temporal) nesting in which the assessed system fits and interacts.

With this extended vulnerability framework, there is formal recognition that macroforces - from both broad-scale environmental and human systems within which the local system resides come together to affect the local system and simultaneously influence the pressures that act upon it. Different pressures across scales come together in various sequences to create unique "bundles" of stress that affect local systems. A major hypothesis holds that when stresses or perturbations emanating from the environment coalesce with those arising from society, significant consequences can result. For example, economic depression reduces society's capability to develop or maintain pre-emptive coping measures to reduce the impacts of drought, such that the co-occurrence of drought and economic depression synergistically enlarges the vulnerability of the system.

The risks resulting from such vulnerabilities emerge from multiple sources and at different scales. These risks cascade through interacting human and environmental systems to create adverse consequences. These interacting systems exhibit conditions that make them sensitive or resistant to the level of risk confronting them, and, depending on the degree of sensitivity, prompt the system to activate its coping and response mechanisms. These mechanisms either attempt to alleviate stresses on the system directly through increased preemptive measures (e.g., building dikes to keep out floodwaters), or, alternatively, they may feed back into and adjust components of the social and ecological system itself (e.g., state-sponsored monetary safety nets for households, or successional growth in a disturbed forest). Before preemptive adjustments are brought into play, the human-environment system and any system adjustments previously made, jointly feed back and change the set of stresses and perturbations to which the system is exposed (e.g., land uses feed back in response to land degradation, land-cover adjusts in response to regional climate change, income can be redistributed in response to an expanding underclass).

Stresses or perturbations that exceed a system's ability to cope and respond lead to impacts that can, in turn, affect resources and mechanisms for further coping. When impacts are sufficiently significant, they may trigger more fundamental changes in the system, described as adaptations (in the face of reduced precipitation, a human community may shift from a rain-fed cultivation economy to ecotourism; a closed woodland ecosystem may become an open savanna).

Mechanisms or strategies for adaptation are not restricted to the scale of the system. The system may adapt to stresses by feeding back on the macroforces from the broader environment, polity, or economy within which the system resides (e.g., increased $\mathrm{CO}_{2}$ emissions may alter climate sufficiently to cause local political pressure that triggers changes in national policies, reducing $\mathrm{CO}_{2}$ output, thereby moderating potentially greater future climate changes). 


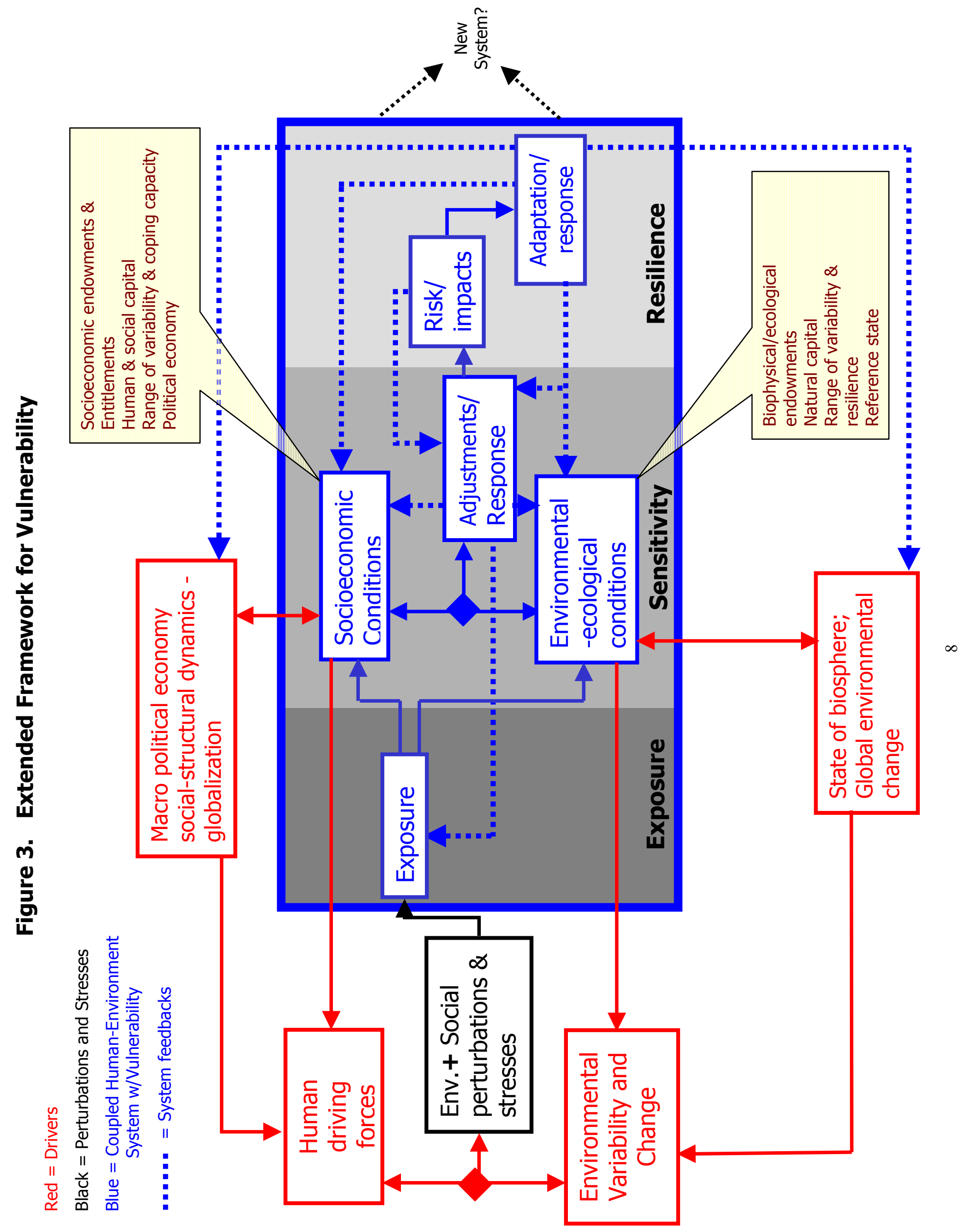


The proposed vulnerability framework is complex, yet it provides an overall structure within which various existing conceptual frameworks and models can be better evaluated, and from which the development of improved models and applications can draw for guidance.

Here we were particularly interested in testing these aspects of the extended framework: Do new insights about vulnerabilities emerge if multiple, synergistic stresses and perturbations are considered on one side of the equation, and multiple, synergistic physical and social characteristics of the exposed system are considered on the other side? Does such a "gap analysis" - comparing "stress bundles" to particular system characteristics that are exposed bring forth new knowledge about stresses to which the system has greatest vulnerability? What are the relative levels of importance of formal versus informal coping capacities? Are there real data limitations that restrict the practical application of the extended framework? And finally, does the framework's complexity hide rather than illuminate important relationships in the system that may either create or dampen vulnerability?

\section{The Case Studies}

In order to preliminarily assess the utility of this extended vulnerability framework, we examine three case studies of global coastal cities in light of climate hazards: Mumbai, India (formerly Bombay); Rio de Janeiro, Brazil; and Shanghai, China. Each of these cities have urban agglomerations in excess of 10 million people, the threshold that the United Nations applies to designate "megacities," and they each represent important national and regional engines of economic development and innovation.

This paper addresses current and future vulnerability to climate hazards. The respective sections provide baseline information on climate in each of the cities. To assess future vulnerability, we use standard sets of climate change and sea-level rise scenarios. Figure 4 provides projected temperature changes by season for reduced emissions ("sustainable path") and increased emissions ("business as usual") scenarios. Compared to temperature changes, precipitation changes are considered to be more difficult to accurately model, and therefore are not included here, except in the form of a map of projected runoff in Figure 5. ${ }^{1}$ Projections of sea-level rise due to melting of land-based glaciers and polar ice caps range from 0.2 to $0.9 \mathrm{~m}$ by 2100 (Nicholls 1995). We adopt a common projected sea-level rise of $50 \mathrm{~cm}$ by 2050 , though local variations in land subsidence will affect the relative sea-level rise in each location. Shanghai, for example, is located in areas of subsidence, and experts point out that the local effects could exacerbate sea-level rise in certain locations (Bird 1995).

These global cities are located in very different physical environments which makes for interesting comparisons. The climate of Mumbai is tropical moist, Rio is sub-tropical wet and dry, whereas Shanghai is on the border between sub-tropical and warm-temperate. Shanghai is located at the mouth of a major river (the Yangtze), and all are coastal cities that have significant portions just above sea-level. Two of the cities, Mumbai and Shanghai, are subject to hurricane (tropical cyclone) landfalls at least once a year (Nicholls 1995).

\footnotetext{
${ }^{1}$ Runoff closely follows precipitation; note, however, that another map in the same IPCC report shows very different patterns of runoff based on a different climate model (Hadley's CM2 ensemble mean instead of the Hadley CM3 model results portrayed in Figure 2).
} 
We focused on collecting data in the categories shown in Table 2 to explore climate hazard vulnerability for these three global cities. Note that data on stresses and perturbations include both climate and social components, some of which arise endogenously to the system. Likewise, system characteristics include elements of physical geography and built infrastructure, coupled with socio-economic conditions that include what we term endowments, and coping abilities (both direct and indirect).

Table 2. Data collected to test the expanded vulnerability framework through a preliminary assessment of the vulnerability of three global coastal cities to climate variability and change.

\section{Stresses/Pertuntations}

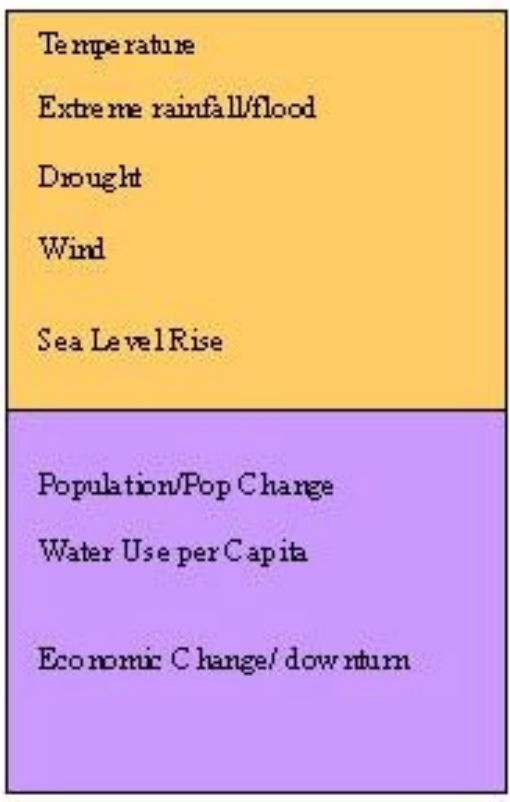

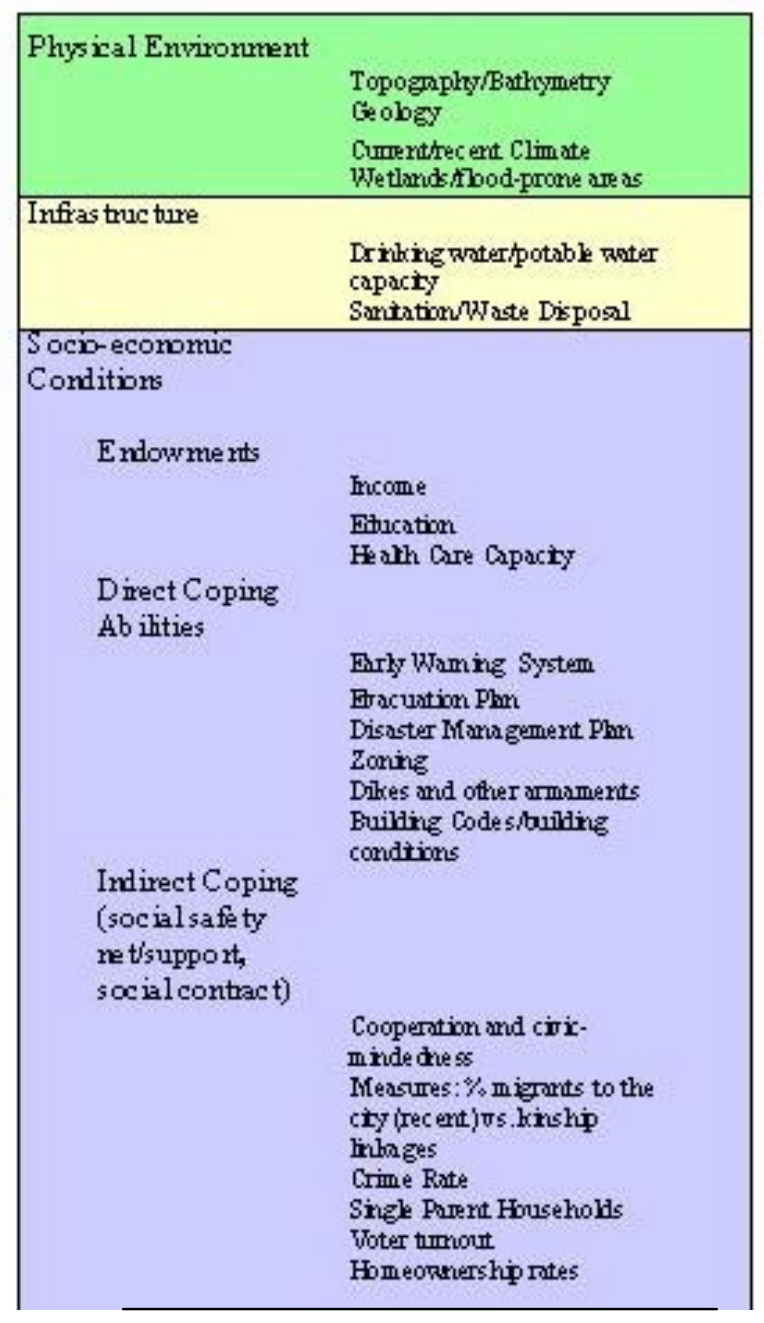


Figure 4. Projected Changes in Temperature for the Global Cities
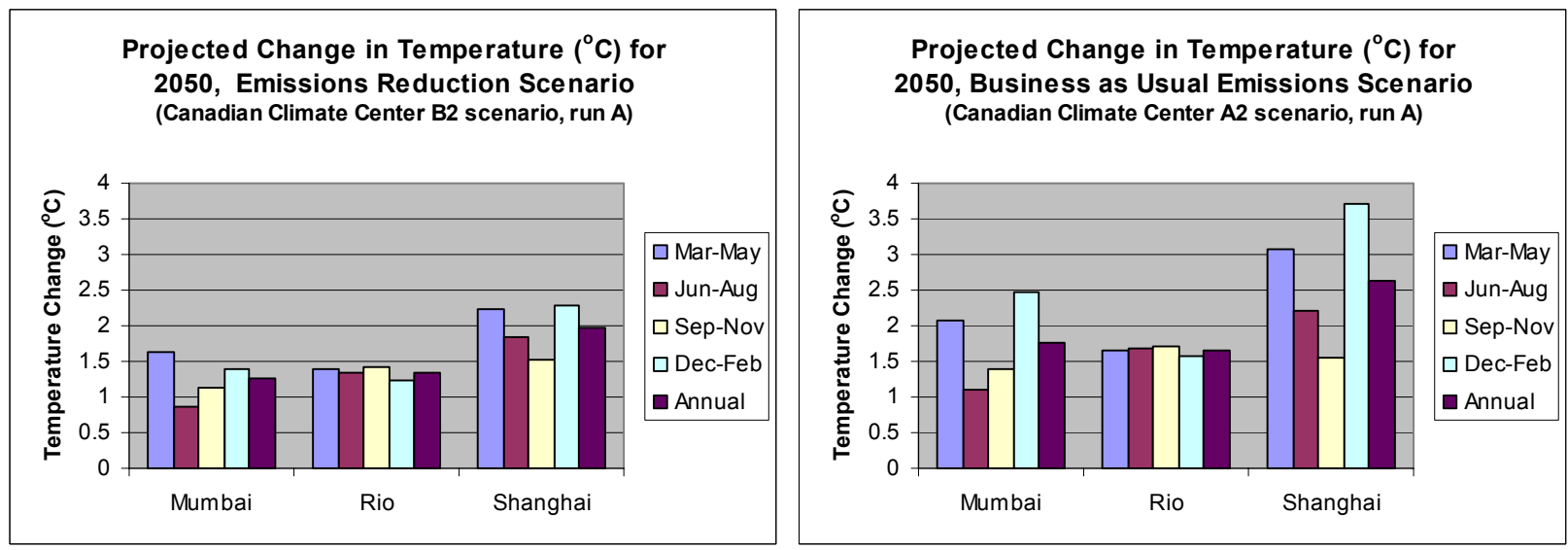

Source: Richard Goldberg, Goddard Institute for Space Studies, 2001.

Figure 5. Case Study Locations Superimposed on Map of Potential Changes in Runoff

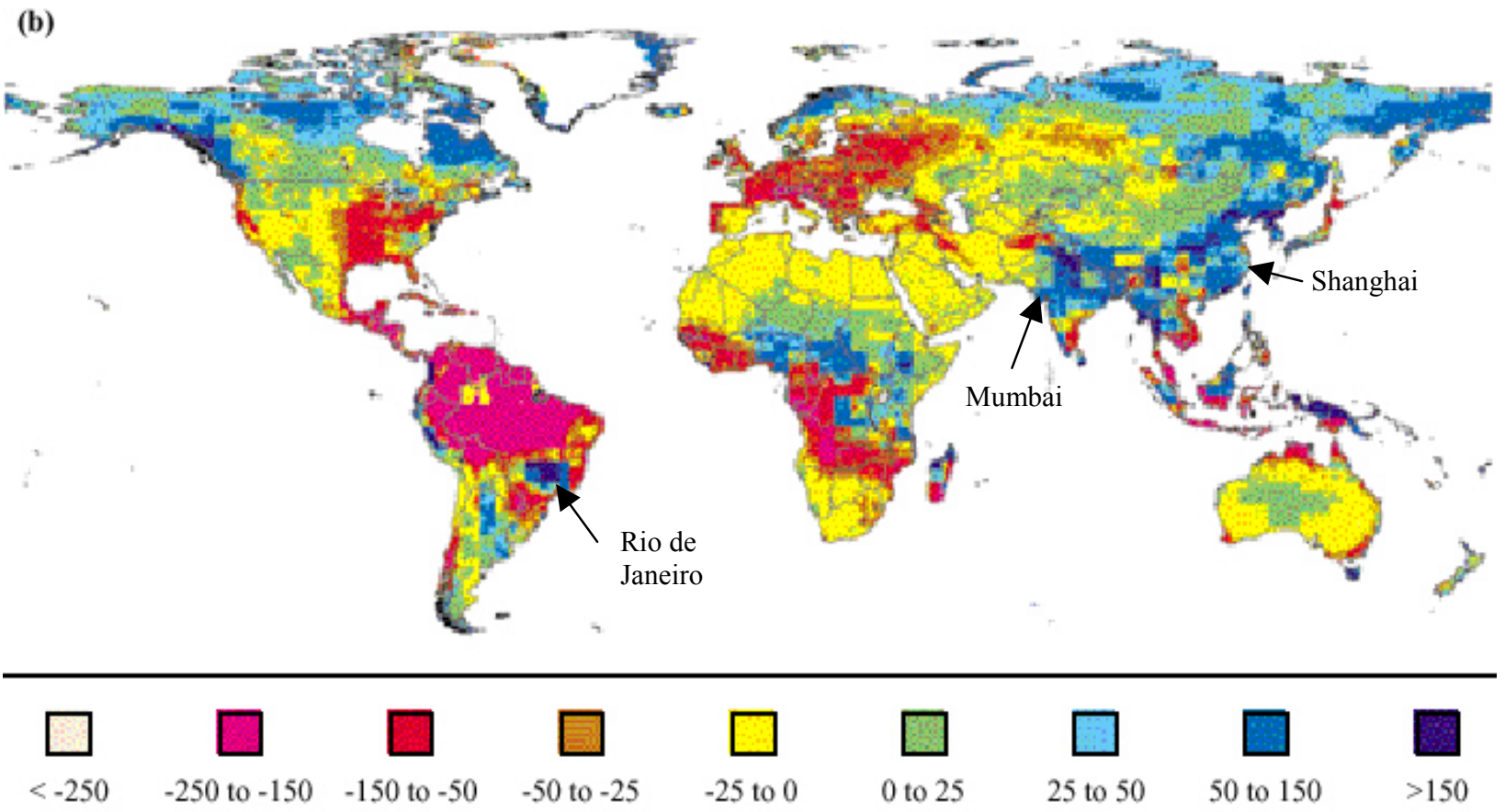

Change in Annual Runoff $\left(\mathbf{m m ~ y r}^{-1}\right)$

Source: IPCC Third Assessment Report - Working Group II Technical Summary, 2001 


\subsection{Mumbai}

Mumbai is the largest and most economically important city in India. Its 17 million people (1.65\% of India's total) contribute roughly $17 \%$ of India's income tax, and $37 \%$ of India's corporate taxes annually, and generate 30\% of India's GDP (Bombay First 2001, Hutchinson Encyclopedia 2000). Mumbai host's India's largest stock exchange (Asia's oldest), its largest high-tech center, the world's most prolific film industry, the world's largest metro-suburban rail system, and Asia's largest squatter community (Demographia 2000). Across the bay from the old city, Navi Mumbai (New Mumbai) is taking shape as the world's largest totally planned city. Unfortunately, Mumbai is also likely to be highly vulnerable to climate change with its downtown located on a flood prone, poorly drained peninsula composed largely of landfill. Among the most vulnerable are the approximately one half of the city's residents who live in squatter communities, many of which are located in low lying areas without adequate sanitation or water supplies. Finally, these vulnerabilities are compounded by Mumbai's location over several seismic faults as well as its unsanitary methods for disposal of raw sewage and industrial wastes into the waters and air surrounding Mumbai.

\subsubsection{Physical Environment}

The Portuguese were first attracted to Mumbai, known then as Bom Bahia ("good bay" in Portuguese), for its excellent harbor and the opportunities for trade with several communities on islands in the harbor. The British gained control of Bombay from the Portuguese in 1661, and as trade and population increased, the need for additional land led to the filling in of the shallow waters and tidal mudflats connecting the original seven islands with rock and dirt from the tops of the island's own hills, between 1784 and 1845. Today landfill lies underneath the majority of the center city of Mumbai, containing the stock exchange, the main train stations and train lines, and numerous high rises. Further inland in the suburbs, where most of the population now lives, elevation rises. However much new settlement, industrial, residential, and commercial, has occurred along the coastal areas of "Greater Mumbai," which are low lying and flood prone (Mumbai Pages 1999)

Mumbai's climate is tropical with temperatures ranging between 16 and 33 degrees Celsius. Temperature and rainfall are strongly effected by the Indian Monsoon, which normally starts in June and ends around the middle of September. Approximately 2,500 mm of Mumbai's 2,700 $\mathrm{mm}$ of rain comes at this time, with flooding common when spells of heavy rainfall coincide with high tides or storm surges. These heavy rain events are sometimes the result of tropical cyclones that occasionally pass near or directly hit Mumbai (Mumbainet 2001, The Times of India 2001)

\subsubsection{Built Environment}

Mumbai has a diverse built environment with unique combinations of urban problems associated with its drainage system and its squatter communities, including building collapses, likely future water shortages, and poor sewage disposal. 


\section{Drainage}

Most landfill areas (i.e. most of the old city) are prone to flooding during the monsoon, especially when heavy rains combine with high tides or storm surge (The Times of India 2001). Even in wealthy areas, drains are often blocked by trash and debris, and monsoon flooding often shuts down Mumbai's commuter rail lines, which an estimated 6.2 million people depend on each day (Geocities 2000). Flooding of this type would likely increase with sea level rise, necessitating major upgrades in drainage systems and also possibly increasing the elevation of major rail lines. Projects are already underway to upgrade the drains that run along the rail lines and to demolish squatter communities along rail lines that contribute to clogged drains. However, this work was not designed with sea level rise in mind. A 1996 national study ranking India's coastal zones by their vulnerability to sea level rise found Mumbai to be the most likely to experience damage (TERI 1996).

\section{Squatter communities}

It is estimated that $55 \%$ of Mumbai's population lives in squatter communities, locally referred to as slums, roughly half of which are severely dilapidated. Many squatter structures are single story and made of salvaged materials. Nevertheless, population densities for roughly one half of Mumbai's squatter communities are estimated to be as high as 94,000 people per square kilometer. This compares with 45,989 people per square kilometer for Mumbai as a whole, 9,998 people per square kilometer for New York City, 4,640 people per square kilometer for Rio de Janeiro, and 2,220 people per square kilometer for the greater Shanghai district (Demographia 2000, MIUL 2001). Mumbai's squatter communities suffer from inadequate access to potable water and sanitation, with the World Bank estimating that 170 persons depend on each public latrine in these areas, and that one third of the 35,000 latrines in Mumbai are out of service (World Bank 1996). Even without sea level rise, many squatter communities in Mumbai are already flooded with frequency as they are often located in low-lying coastal areas and along stream banks - areas most likely to experience floods. Flooding is common even in Mumbai's squatter communities on higher ground, as the large amount of refuse and debris in these areas tends to clog storm sewers and cause a backup of water that would otherwise run off or find its way to storm drains (Sharma 2000). Landslides are another threat to squatter communities that are near or on the few hillsides in the city. These landslides usually occur during heavy monsoon rains as hillsides become saturated with water. On July 122000 between 60 and 160 people were killed by such a landslide (Indian Express 2000).

Mumbai authorities have historically dealt with the problems caused by squatter communities by demolishing them and forcibly relocating the inhabitants to new areas in the suburban fringe. Increasingly, non-governmental organizations (NGOs) are organizing to meet the needs of squatters dwellers for better access to sanitation and water, but their efforts are still limited in scope, and their impact is quite small, especially with regard to some of the squatter communities most vulnerable to sea level rise and flooding. This is because funding from the Indian government cannot be used in violation of zoning regulations that prohibit residential development in coastal areas (Sharma 2000). While restricting coastal zone settlements theoretically reduces settlement in vulnerable areas, in practice this has not deterred such settlement and has merely stalled efforts to make these areas less susceptible to damage and loss of life. However, lifting the coastal zone regulation would likely encourage more settlement in 
flood-prone areas, exposing even greater numbers of people to flooding, disease, and economic ruin. This represents something of a no-win situation.

\section{Building Collapses}

Mumbai has become notorious for frequent collapses of buildings, especially high rise apartment buildings, due to structural failures. Causes include bribery of building code inspectors and the effects of the Monsoon. The structural integrity of buildings in Mumbai may also be affected by the city's location over several seismic fault lines. Buildings in the landfill areas of the old city showed cracks after the Gujurat Earthquake of 2001 (The Observer of India 2001). While some government and public buildings have been re-enforced, some 36 per cent of Mumbai's buildings are judged to be in the "risk category" in case of an earthquake (Economic Times 2001).

\section{Drinking Water/potable water capacity:}

Mumbai's water supply consists of several artificial rain-fed lakes located in the suburbs to the north of the old city. While their location on hills makes them less susceptible to impacts from sea level rise, their total dependence on rainfall means that increasing variability in precipitation could threaten this water supply. Recent attempts to upgrade Mumbai's water supply have been considerable, but progress has been nullified by a growing population. The World Bank's Bombay (Mumbai) Water Supply and Sewage Disposal Projects, which were implemented between 1975 and 1995, increased the city's water supply from 260 to 650 million gallons per day. During the same period, however, Mumbai's population increased 80 percent, leaving per capita water availability unchanged at about 250 liters per day. An antiquated, leaking and partially un-metered water delivery system are also cited by The World Bank as major problems holding back improvement of the city's water system (World Bank 1996).

\section{Pollution}

Both air and water pollution have been identified as major problems in Mumbai, by both local authorities such as the Mumbai Metropolitan Region Development Authority (MMRDA), and by The World Bank. The World Bank describes Mumbai's air pollution as "severe" and with regard to Mumbai's water pollution states that "about 75 percent of all sewage is untreated and discharged to local waterways and coastal waters, causing extensive environmental hazard" (World Bank 1996).

\subsection{3 - Socioeconomic Conditions}

\section{Endowments}

While Mumbai has by far the largest concentration of wealth in India, this wealth is highly concentrated and unevenly distributed in the city. Per capita income, adjusted for purchasing power parity, is estimated to be three times that of India as a whole, or equal to US\$ 6,600 (CIA 2001). Mumbai accounts for $1.65 \%$ of India's total population, but it is estimated that the city accounts for $17 \%$ of the income tax and $37 \%$ of corporate taxes collected throughout all of India in 2000. Still, income distribution in the city emerges as a major problem. Haq and Haq (1998) estimate that roughly two thirds of the city falls into the low income category. Sharma (2000) states that in 1989, 62\% of households in the Mumbai Municipal Region earned less than $\$ 120$ per month, and that one quarter of all households in the area were under the poverty line of $\$ 48$ 
per month. Unemployment is estimated to be as quite high, largely due to Mumbai's decline as a manufacturing center (World Bank 1996).

Mumbai's population growth is estimated at $4.2 \%$ per year, with current population estimated at 17 million (Demographia 2000). The Indian Census of 1991 put Mumbai's population at roughly 14.4 million, with 3.2 million in the old central city, 6.7 million in its immediate suburbs, and 4.5 million in the rest of the Mumbai Municipal Region (MMR) (Demographia 1991). By 2011, these figures are estimated to rise to 22.4 million, with 12.9 million in the old city and its immediate suburbs, and 9.5 million in the rest of the MMR (MMRDA Basic Statistics).

\section{Direct coping}

Mumbai is the headquarters for the state of Maharashtra Disaster Management Plan. An Emergency Operations Centre (Central Control Room) in Mumbai is the main hub for a network connected with a variety of sophisticated technologies aimed at emergency planning and disaster management. Multi-hazard response plans, financed by the UK's Department for International Development (formerly the Office of Development Assistance), are also in place in Mumbai as well as six other centers across the state. There are multi-hazard response plans in place for each district, including risk assessment and vulnerability analysis with reference to earthquakes, floods and cyclones, epidemics, road accidents, fires, and chemical and industrial disasters. These systems also contain a multi-hazard response structure, capability analysis, inventory of resources, mitigation strategies, and a directory of personnel and institutions in the districts with their contact addresses, telephone and fax numbers (Maharashtra Disaster Management Plan An Overview ). Nevertheless, the continued occurrence of catastrophic-level flooding and large human impacts from such flooding in Mumbai during the annual Monsoon, indicates that serious problems persist. Moreover, the various ongoing landfill projects of various Mumbai development authorities suggests that a more prevention-oriented approach to disaster avoidance and reduction is lacking (MMRDA Planning).

\section{Industrial zoning}

Regulations are in place that prohibit the location of new industries in the old center city. This has been done to reduce congestion and pollution, and discourage further dense settlement in this old portion of the city that has an antiquated built environment. These regulations have an added, and as yet unappreciated, benefit of decreasing settlement on landfill areas which are susceptible to flooding and potential shifting due to sea level rise and increased storm frequency. However, some of the new settlements that industries and people are being relocated to are also in low-lying coastal areas that may be similarly susceptible to sea level rise and storm surge (MMRDA Backbay). There are also claims that these areas have higher rates of respiratory and other ailments due to highly polluting facilities being located there (MMRDA Bandra-Kurla, Mumbai Pages 1999, MMRDA Masterplan).

\section{Indirect coping}

Despite its many chaotic qualities, Mumbai is socially highly organized, a quality that mitigates some of the city's vulnerability to natural hazards. For example, in 1999 a squatter organization in Mumbai, the National Slum Dwellers Federation (NSDF), was placed on the UNDP's prestigious Scroll of Honour for its work in the collective design and construction of low cost 
houses and toilets, and waste disposal systems that have reduced waste output from select squatter communities in Mumbai by up to 70 per cent (UNDP Press release). NSDF and many similar organizations in Mumbai have built strong partnerships between poor communities, NGOs, and various levels of government (SPARC 2000).

Another important aspect of Mumbai's social support system is the city's ability to garner resources from abroad. As the wealthiest and most cosmopolitan city in India, and as the center for India's film industry (the world's largest in terms of output), Mumbai looms large in the minds of Indian's living abroad. This community is recognized throughout India as a key to the country's overall development, and Mumbai's unique ability to broadcast its problems and needs to this community may prove an important factor in reducing the city's impacts from climate hazards. This may be especially true in the case of dramatic perturbations, such as sea level rise and associated flooding, that could threaten Mumbai's status as the leading city of India.

\subsection{4 - Likely Future Climate Hazards and Overall Vulnerability Assessment}

The Canadian Climate Center's A2 (business as usual) scenario predicts an average annual temperature increase of $1.75^{\circ} \mathrm{C}$ and the $\mathrm{B} 2$ (sustainable path) scenario predicts a roughly $1.25^{\circ} \mathrm{C}$ increase by 2050 (see Figure 1). This increase is similar to that predicted for Rio but lower than the increases in New York or Shanghai. Mumbai is predicted to have an average annual decrease in precipitation of two percent for the A2 scenario and an increase of two percent for the B2 scenario. The predicted sea-level rise of $50 \mathrm{~cm}$ by 2050 could prove seriously damaging for Mumbai.

\section{Potential impacts of precipitation extremes}

The A2 (business as usual) scenario may engender water shortages in Mumbai given the city's complete dependence on rainfall for its water supply. The fact that both scenarios predict a decrease of rain during the first part of the year (January-August) suggests that droughts will become more common throughout Mumbai's surroundings, though predicted reductions during the monsoon season are less dramatic. Furthermore, both scenarios show an increase in rainfall from September to November, which may mitigate water shortages from reduced monsoons. If droughts do increase in severity, this could trigger migrations from surrounding agricultural areas (a common occurrence during drought years), which could tax the city's resources in the context of multiple climate change impacts.

\section{Coastal/Marine issues}

A 1996 study undertaken by the Tata Energy Research Institute put the cost to Mumbai of a one meter sea-level rise at US\$71 billion (TERI 1996). The study concluded that US\$24 million invested in protection against sea level rise would reduce the economic impact by about US\$33 billion dollars. The predicted rise in sea level of $50 \mathrm{~cm}$ would probably have a similarly disastrous impact on Mumbai. Flooding would increase dramatically in the many coastal and low-lying areas where many squatter communities are located. Moreover, shifting would likely occur in the subsurface of the landfill areas resulting in many buildings becoming uninhabitable due to structural instability. Mumbai's landfill areas contain a mixture of high value commercial properties, such as the stock exchange, important public facilities, such as the main train stations and train lines, numerous high value residential high-rises, and a number of squatter 
communities. The few hills, formerly islands, that were not leveled to create the landfill that the majority of the city was built on, contain mostly upscale residential areas long prized for their relative immunity to flooding. These areas lack the commercial potential to take up slack should the landfill areas go into decline. However, provided that sea level rise occurs gradually and was recognized early enough, Mumbai might be able to mitigate damages, perhaps by shifting much of the old city to the adjacent suburbs or Navi Mumbai.

\section{Overall Vulnerability}

Figure 6 provides a schematic diagram of our findings from applying the extended framework of vulnerability to Mumbai, based on preliminary data. What emerges from using the broader framework is the specific identification of the set of stresses and perturbations that converge to create greatest stresses on Mumbai, for which certain conditions within Mumbai come together to produce vulnerabilities to these particular "stress bundles." For example, extreme rainfall and floods converge to produce stresses. Mumbai's characteristics of topography (flat), geology (unconsolidated fill material), many wetlands and flood prone areas, the city's building conditions (not meeting building codes, squatter dwellings, previously flood-damaged buildings), and poor sanitation and waste treatment and removal capabilities. This particular "bundle" of stresses "collides" with this set of socio-environmental conditions of Mumbai such that vulnerabilities emerge for the system. This type of "gap analysis" reveals where vulnerabilities will likely arise out of the larger list of stresses/perturbations and system conditions.

In addition, a "stress bundle" composed of population (large and growing), projected sea level rise, and economic stresses, converge to create some particularly problematic issues for Mumbai. This is because of a set of characteristics for Mumbai itself: the lack of dikes and other coastal armaments for dealing with sea level rise, a weakness in disaster preparedness at the scale of sea level rise, building conditions (not meeting building codes, squatter dwellings, previously flooddamaged buildings), and low incomes that do not allow the city to increase building conditions to the level required, nor to better develop and fund disaster preparedness. Together, these issues put Mumbai in front of an issue with which it likely will have very little ability to control, dampen or mitigate. The dashed arrows in Figure 6 further suggest a reinforcing spiral could emerge for these set of issues, where increasing population comes together with sea level rise and a stressed economy to further damage already weak buildings, undermine efforts to improve disaster preparedness and to build coastal armaments - and in turn - these further erode the economy while sea level rise marches forward. Mumbai's informal coping capacities - because of notably strong social networks and cooperation, emerge as important parts of Mumbai's resistance and resilience in the face of stresses. These informal coping systems are shown in the diagram to help reduce vulnerabilities to some degree for both sets of issues that emerge from this preliminary analysis. Yet, by themselves, these informal coping capacities appear quite inadequate to meet the challenges from climate hazards and population size and growth that now face Mumbai.

Mumbai's overall vulnerability appears to be high. While the city is relatively prosperous compared to the rest of India, and it does have an elaborate disaster management plan in place, the challenges posed by climate change, especially flooding and subsurface shifting in landfill areas are unlikely to be met effectively. In particular, subsurface shifting of the type that Mumbai might face could well overwhelm the adaptive abilities of any city, and particularly one with some of the other important and critical issues that Mumbai now faces. 
Figure 6. A schematic diagram of the key converging stresses/perturbations from climate, population, and economy, and the sets of characteristics of the Mumbai socio-ecological system that come together to create vulnerabilities. The dashed arrows suggest a spiral of reinforcing stresses and system damages that could move the system into even greater harm.

\section{Vulnerability of Mumbai}

To Proiected Climate Change
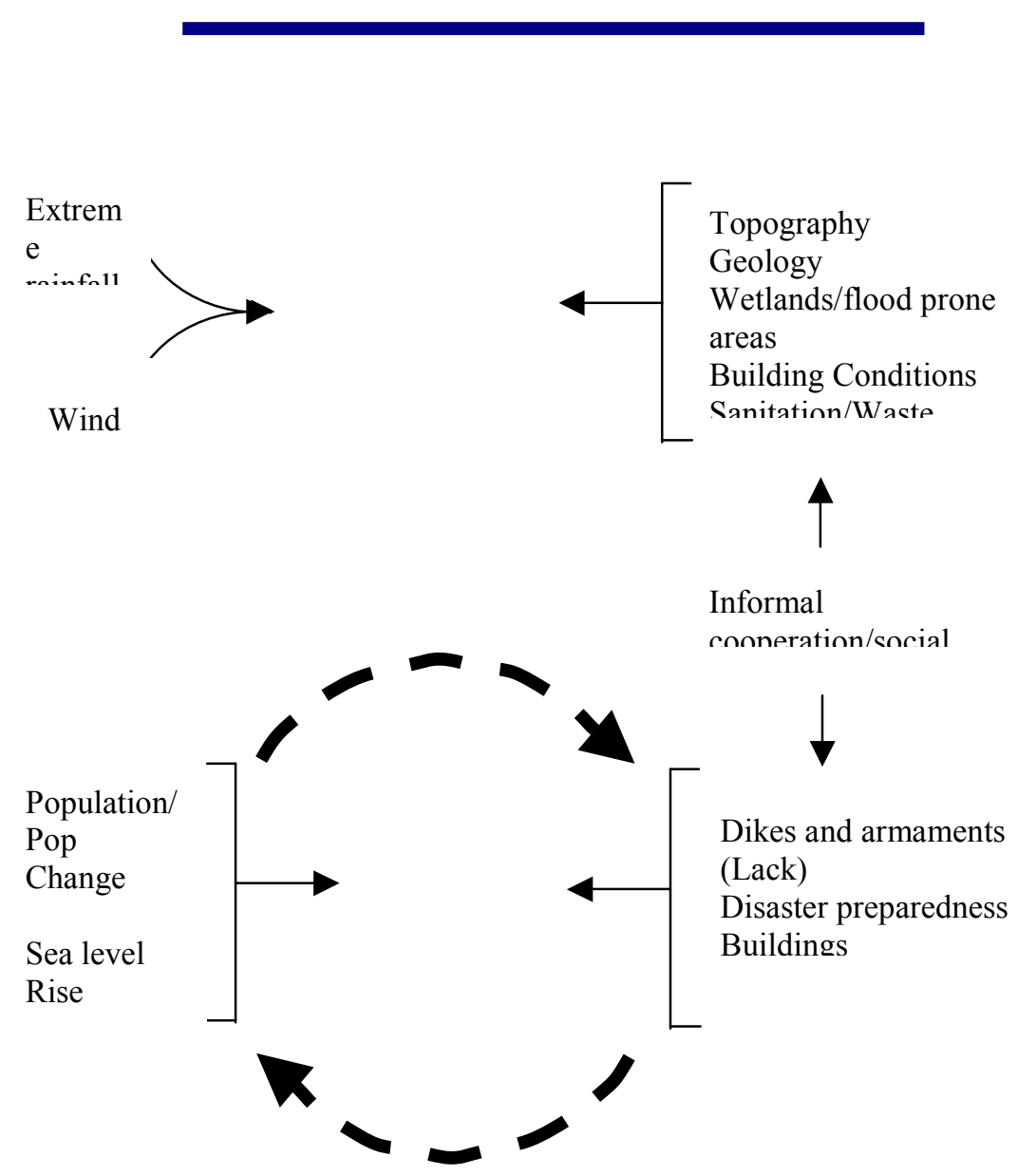

\subsection{Rio de Janeiro}

Rio de Janeiro is a city of just over 10 million people located at approximately $22.9^{\circ}$ South latitude and $43.3^{\circ}$ West longitude with a total area of $1,171 \mathrm{sq}$. km. Guanabara Bay, upon which Rio is situated, faces almost due South. Rio is the second most populous city in Brazil, after São Paulo, and ranks second only to São Paulo in industrial production. This erstwhile capital of Brazil is known for its beautiful beaches and the granitic hills that rise dramatically from sealevel to heights of over 1,000 meters. Yet, Rio faces significant environmental sustainability 
challenges stemming from unregulated settlement in hazardous areas, sewerage disposal, and industrial wastes. These will be exacerbated by potential climate changes.

\subsubsection{Physical Environment}

Rio's dramatic topography has made it more prone to certain types of hazards. When the Portuguese discovered Guanabara Bay in 1501, the coastal mountains were carpeted in thick Atlantic rainforest. As this protective covering has been progressively stripped away to make room for settlements, the thin soils are prone to landslides and the granite and gneiss bedrock has been left exposed to weathering, making it more prone to decomposition and erosion.

The coastline in this area was characterized by lagoons, estuaries, and low lying coastal marshes, many of which have been filled in. The flat topography of low lying areas, combined with lack of drainage, has continued to result in flooding during the summer rainy season (January-March). The few remaining lagoons, mangroves and marshes have been affected by sedimentation, reducing their absorptive capacity during extreme rainfall events. Ninety percent of mangroves surrounding Guanabara Bay have been removed, and intense sedimentation has resulted in the need for dredging to maintain shipping lanes. Rio's beaches, a major tourist asset, are subject to intense erosion during storm events (up to 5 meters recession), but usually recover quickly through deposition of sand laterally along the coast (Muehe 2001). Significant resources are also expended on beach nourishment following erosion events.

The climate in Rio is moderated by the coastal effect, and by its southern exposure and mountain ranges to the North. The mountain ranges block cooler northeasterly winds during winter months, and enhance orographic precipitation during summer months when winds are predominantly southwestly. Rio experiences wet summers (December-March), during which temperatures range average $24-26^{\circ} \mathrm{C}$, and dry winters (June-September), during which temperatures range from $20-22^{\circ} \mathrm{C}$ (see Figure 6). Maximum temperatures rarely exceed $42^{\circ} \mathrm{C}$. From year to year precipitation ranges from 1200-1500 mm, whereas evaporation ranges from 800-1200 mm.

Rio is not impacted by tropical cyclones. However, the city does receive a strong El NiñoSouthern Oscillation (ENSO) signal, and during El Niño years the city receives higher then normal precipitation during the summer months. During one recent El Niño year, 1988, the city was affected by severe floods as a result of two intense periods of rainfall in early February that dropped a total of $480 \mathrm{~mm}$ of rain, one-third the annual total rainfall.

\subsubsection{Built Environment}

Rio's peculiar geography, and the circumscribed nature of suitable building sites, has spawned two kinds of responses. One is the construction of apartment high-rises close to the coastline (e.g., Copacabana, Ipanema and Leblon) and in flood prone areas further inland, and the other is unregulated construction on steep slopes, particularly on the Tijuca mountain range. The unregulated construction of favelas (shantytowns or, literally, tenements) has a long history, and stems from the invasion of both private and public urban lands by poor urban squatters who become de facto (and in some cases de jure) owners of plots of land (Fernandes 2000). Many favelas have evolved over time from ramshackle collections of wooden shacks lacking even the 
most basic amenities to organized communities of largely concrete housing with cemented walkways, electricity (through licit and elicit connections), plumbing, sewerage, and other services.

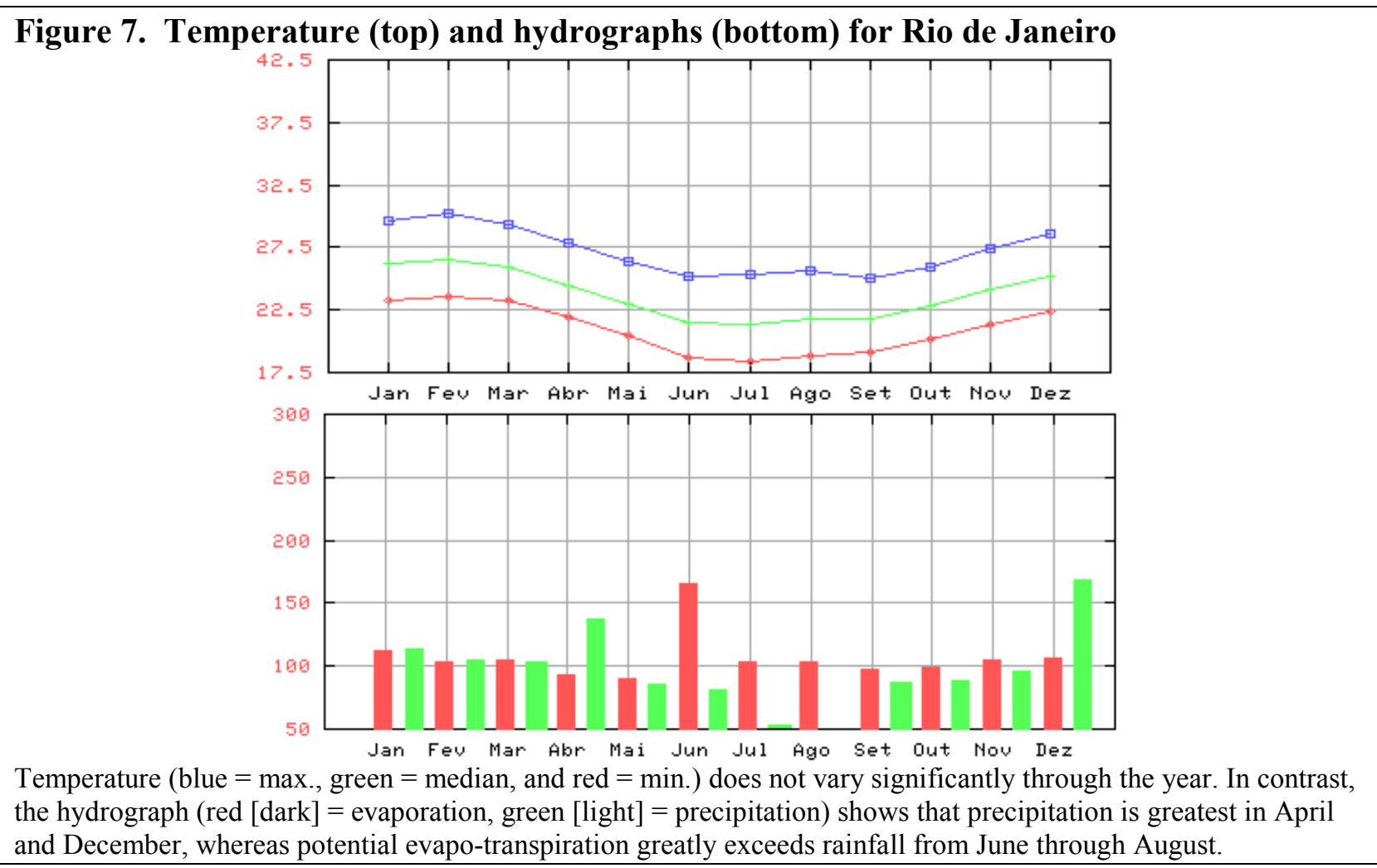

Though favelas always suffered during rainy seasons, the paving of walkways has had the effect of increasing runoff to the point where one resident said that water is often ankle or knee deep between the houses. Thus, drainage is a problem. Runoff from communities on steep hillsides, including Petropolis and favelas on the Maciço da Tijuca massif, are channeled down cemented and quasi-natural water courses to the narrow coastal lowlands, where they join canals whose limited flow capacity causes frequent flooding. By contrast, the Baixada Fluminense, a large marshy lowland somewhat removed from the steeper parts of the city, has had reasonably adequate drainage since the 1930s (Cunha and Santos 1993).

In terms of services, the city has a reasonably clean and reliable water supply that is piped in from rivers in Minas Gerais state to the north (Cunha and Santos 1992; Muehe 2001). Over 84\% of the population is supplied with water. Eighty-three percent have their own sanitary installations. Ninety-four percent of the population has access to electricity supply at home. Electricity is largely generated by Brazil's major hydroelectric facilities, which supply $92 \%$ of the country's electricity needs. A drought period earlier this year led to electricity shortage throughout the country, and consumers in Rio de Janeiro were ordered to cut consumption by 20 25\% (Downie 2001). 
Waste disposal is a significant problem. Trash disposal for favelas remains haphazard, with some estimates that 5,400 tons/day or more end up in rivers and drainage channels, blocking channels during peak flow (Baptista de Araújo 1994). This compares with 7,000 tons/day that end up in city dumps, mostly at the margins of Guanabara bay. Daily discharges into the bay include 465 tons of organic matter, 68 tons of which receive adequate treatment, and 9.5 tons of oil. The Iguacu and Estrela Rivers which drain the Bay's watershed are often anoxic and produce a strong hydrogen sulfide smell (Kreimer et al. 1993).

Guanabara Bay is surrounded by a mixture of industrial and residential land uses. As the second largest industrial zone in the country, it has 10,000 industries, 10 oil terminals, 12 shipyards, and two oil refineries (Kreimer et al. 1993). Petrobras, the Brazilian oil company, has numerous offshore drilling platforms near Rio, and uses Rio as its primary distribution point. Traversing the bay is also a giant causeway leading to Niteroi, and two airports are located just above sea-level on the margins of the bay.

\subsubsection{Socioeconomic Conditions}

\section{Endowments}

Although Rio's product per capita is roughly double the national average (see Table 3), its income distribution is highly skewed. The existence of pockets of extreme poverty side-by-side with some of the most affluent neighborhoods is characteristic of the city. Rocinhas, among the oldest and largest of Rio's favelas, clings precariously to steep slopes of the Tijuca mountain range just above Gavea, one of the city's wealthiest neighborhoods. It is estimated that 1.1 million people live in favelas, or 20 percent of the municipality's population.

Table 3. Socioeconomic Statistics on Rio de Janeiro

\begin{tabular}{|l|l|}
\hline \multicolumn{1}{|c|}{ Indicator } & \multicolumn{1}{c|}{ Value } \\
\hline Metropolitan Area Population & 10.9 million \\
\hline City Product/capita & $\$ 9,399$ (compared to Brazilian GNP of \$4,792 p.c.) \\
\hline Unemployment rate & $5.0 \%$ \\
\hline Percentage employed in informal sector & $40.0 \%$ \\
\hline Under 5 mortality rate & 40 per 1,000 \\
\hline Percentage solid waste that goes to landfills & $73 \%$ \\
\hline Homicide rate & 4 per 1,000 \\
\hline Theft rate & 54 per 1,000 \\
\hline
\end{tabular}

Source: IGBE (2001) and United Nations Centre for Human Settlements (HABITAT), Global Urban Indicators, Version 2, http://www.unchs.org/guo/gui/gui.asp (accessed Sept. 3, 2001).

According to the 2000 census, the population of Rio metropolitan area is 10.9 million, with 5.8 million residing in the municipality (IBGE 2001). Population density in the latter is 4,640 persons per square kilometer, but densities in the smaller administrative units of the metro area are between 8,000 and 12,000 persons/Km2 (IBGE 2001), indicating that some parts of the city have significant population concentrations. Although rapid population growth of $3.8 \%$ was predicted for the past decade (Baptista de Araújo 1994), the recent census figures suggest that the rate may have been slower. Corrêa do Lago (1999) notes that the metro area received 758 thousand migrants from 1970-80, but that from 1980-91 the number had decreased by 24 percent 
to 573 thousand. It is possible that continued declines in migration account for the somewhat lower than expected overall population growth.

\section{Direct coping}

The state of Rio de Janeiro has a Civil Defense of 15,000 members, including the fire department, emergency medical service, sea rescue service, and the community relief department. Brazil's State Environmental Engineering Foundation (FEEMA) is responsible for coastal monitoring and land-use zoning in the state. Baptista de Araújo (1994) urges more microplanning for disaster management such as occurred under the Rio Reconstruction Project, which was implemented in the wake of the 1988 floods.

In terms of zoning, until recently there was little effort to segregate industrial or waste disposal activities from residential areas. This could result in potential vulnerabilities, particularly should flooding lead to dispersion of pollutants to surrounding areas. New regulations have been put in place that restrict building in hazard-prone areas, and according to Kreimer et al. (1993), "major emphasis has been placed ... on command and control mechanisms to regulate urban growth." Efforts have also been under way for several years to "regularize" favelas through various government programs to undertake cadastral surveys, grant deeds to de facto owners, and provide basic infrastructure. These same plans limit the further expansion of favelas in flood prone or steeply sloped areas.

\section{Indirect coping}

There are several issues that weaken Rio's indirect coping capacity. These include official corruption and political tensions between federal, state and municipal governments; and large migrant communities with low tenure security, decreasing levels of social cohesion, and low levels of education.

Geddes and Ribero Neto (1992) write of the widespread corruption during the Collor administration. According to the authors, the weakening of the executive branch's ability to build coalitions and assure the loyalty of supporters in Congress has created strong incentives to exchange material benefits (in the form of public works projects) for congressional support. Unfortunately, for those jurisdictions (such as Rio de Janeiro) that had leaders in rival political parties, this led to denial of federal financing for public works projects, and even problems in the implementation of disaster relief programs. Allen (1994) describes how political wrangling between federal, state and municipal authorities negatively affected relief and reconstruction efforts after the floods of 1988. She writes, "political rivalry between State and municipal government, between both of them and the federal government, and even at managerial level within the Caixa Economica Federal, exacerbated problems of project implementation, involving an 18 month delay in starting the reconstruction plan." She claims that the poor were largely left to their own devices to build their lives again after those disastrous floods.

Rio has a large migrant population from the poorest parts of Brazil's arid northeast region. The fact that many of them do not have personal experience with mudslides or mass wasting may account for building practices. Migrants push up hillsides in search of new land, consistently eating away at the vegetation cover on the slopes above the favelas, despite government efforts to cordon off such areas to prevent further development. An improved local environmental 
knowledge and understanding of slope dynamics might cause favela dwellers to reconsider such activities.

In terms of social cohesion, the favelas do have some rudimentary organization, including neighborhood watches and self-improvement societies. However, the level of cohesion has apparently declined over time as the prevalence of drug-related crime and violence has increased. One observer speaks of the prevalence of young, predatory gangs (Maimon 2001), which contrasts to the kinds of gangs that at one time had a sense of allegiance to favela residents, and would even provide protection for their own.

\subsubsection{Likely Future Climate Hazards and Overall Vulnerability Assessment}

The Canadian Climate Center's A2 (business as usual) and B2 (sustainable path) scenarios predict roughly equal average annual temperature increases of $1.5^{\circ} \mathrm{C}$ by 2050 (see Figure 1). This increase is about the same predicted for Mumbai, but is lower than that of Shanghai. Unlike the other cities, the same approximate $1.5^{\circ} \mathrm{C}$ increase is predicted across all four seasons. As mentioned earlier, projected precipitation changes are less reliable, though Canadian A2 and B2 scenarios suggest declines of 7 percent and 2.5 percent, respectively. Rio may have precipitation decreases of 13 percent in the winter months (June-Aug) and the spring (Sept-Nov) for the A2 and $\mathrm{B} 2$ scenarios, respectively. Sea-level rise, as mentioned earlier, is predicted to be on the order of $50 \mathrm{~cm}$ by 2050 .

\section{Potential impacts of precipitation extremes}

Given the potential decreases in precipitation during winter and/or spring, it is likely that these seasons will suffer from increased drought. Summer months may also experience drought, as evapo-transpiration increases due to increased temperatures with no offsetting increases in precipitation. Drought conditions could precipitate two kinds of problems. One is water scarcity, particularly if the droughts extend into the Paraíba River basin in Minas Gerais, where Rio obtains the majority of its water. The other is electricity shortages, as were recently experienced throughout the country (Downie 2001).

Although average precipitation during the summer rainy season may decline, increases in seasurface temperature and in the severity of El-Niño/Southern Oscillation (ENSO) events, could result in periodic flooding of the kind encountered during February 1967 and again in February 1988. The 1967 floods were even more extreme than those in $1988-1,985 \mathrm{~mm}$ fell over two days (83 percent higher than average annual rainfall) (Baptista de Araújo 1994). Generally, precipitation extremes are expected to increase in severity with climatic change, and these will have adverse impacts on Rio, given that the city already experiences extreme flooding on a 15-20 year basis. Poor neighborhoods are particularly vulnerable to this kind of flooding; roughly 300 people died and more than 20,000 people were made homeless during each event in 1967 and 1988.

\section{Coastal/Marine issues}

Rio does not suffer from subsidence, so sea-level rise will not be exacerbated by this issue. However, should sea-level rise be coupled with more extreme coastal storms, there is significant likelihood of increased beach erosion, which will affect nourishment costs, and could ultimately 
impact the tourism sector of the economy (Schnack 1993). However, Muehe (2001) indicates that it is unlikely that high rise apartment buildings in Copacabana and Ipanema will be directly impacted by a $50 \mathrm{~cm}$ rise in sea-level, even in the event of storm surges.

As mentioned above, Guanabara Bay has lost most of its coastal mangroves, and significant portions of coastal marshes have been filled in. The potential for mangroves or marshes to retreat inland with rising sea level is impeded by the concentrated development along the coast. This will reduce the capacity of the few remaining wetlands to act as buffers during storm surges.

Rising water temperatures may precipitate algae blooms in Guanabara Bay, especially if efforts are not made to treat discharges into the bay.

\section{Overall Vulnerability}

Figure 8 provides a schematic diagram of our findings from applying the extended framework of vulnerability to Rio de Janeiro, based on preliminary data. We find that there are three stress bundles that are particularly troublesome for Rio de Janeiro. Each coalesces with a particular set of system characteristics to produce vulnerabilities because of gaps in the Rio's socio-ecological system that do not allow it to withstand, respond, or cope effectively with these predicted stress bundles.

Temperature increases come together with drought to put stresses on Rio's drinking water supply. In addition, problems with governance exist that could further hinder the city in developing more robust potable water storage and delivery systems. Extreme and unpredictable rainfalls and floods converge with projected sea level rise to visit stresses that Rio will likely have difficulty handling due to the city's topography (narrow coastal shelf backed by steep mountains subject to mass erosion), poor building conditions, the lack of land tenure for a notable portion of the city's population, poverty coupled with large income inequalities, high rates of crime that reduce social trust, and large problems with sanitations systems and sewerage disposal.

Lastly, sea level rise converges with the tourism-based economy of a beach city to create a third stress bundle of great importance for Rio de Janeiro. This economy and sea level rise together are an issue because of Rio's characteristically narrow beach, which is backed by steep slopes and mountains such that modest increases in sea level will likely visit great harm on the existing beach. In addition, Rio has a lack of dikes and other beach armaments that could protect the beach from modest sea level rise, or even from great storm surges. This situation illuminates a gap between the stress bundle and Rio's ability to resist or cope with it. Because of Rio's economic dependence on beach tourism, such damages will likely have reciprocal effects on the economy that create additional stress on the city. 
Figure 8. A schematic diagram of the key converging stresses/perturbations from climate, population, and economy, and the sets of characteristics of the Rio de Janeiro socio-ecological system that come together to create vulnerabilities. The dashed arrow suggests a feedback of reinforcing stresses that could endanger the area's tourism economy due to loss of the narrow beach zone.

\section{Vulnerability of Rio de Janeiro To Proiected Climate Change}

Extreme rainfall/flood

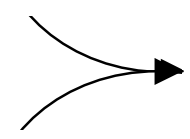

Sea level

Rise

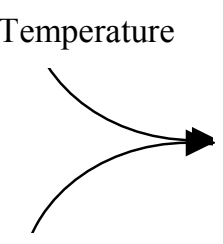

Drough

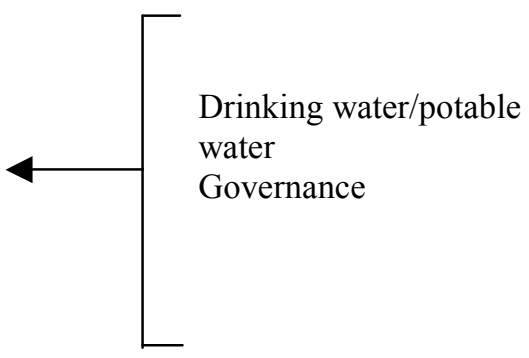

Topography

Building Codes/Conditions

Land Tenure

Poverty/large inequalities

Crime

Sanitation/Sewerage

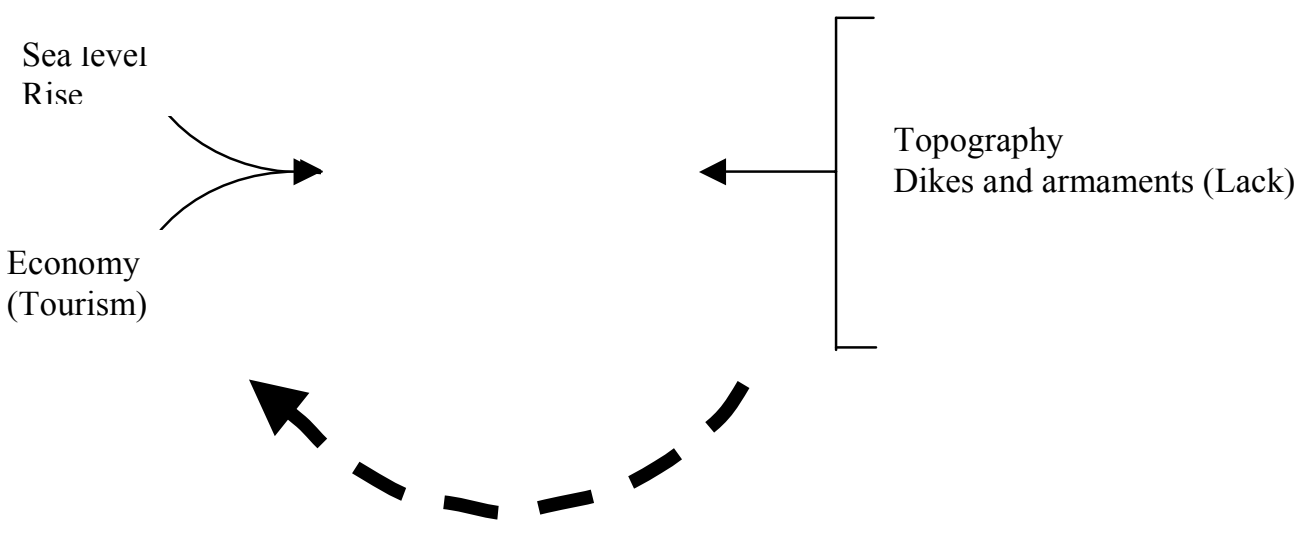


Based on this preliminary assessment, we conclude that Rio suffers from a significant ongoing vulnerability to climate hazards, particularly flooding and landslides. Although civil defense institutions have been set up to cope with natural disasters, underlying structural problems, including political clientelism and spatial segregation based on income, render the city vulnerable to climate hazards. Little in the way of concrete flood protection infrastructure has been set up in the wake of the 1988 floods. It is possible to speak of a highly vulnerable subpopulation that lives in favelas and near water ways, and relatively less vulnerable upper classes that live in high rises in locations less susceptible to inundation. At the same time, climatic changes are predicted that will likely increase the severity of intense rainfall events and raise sea level. Although the economy of Rio de Janeiro is relatively robust, significant portions of GDP will be required for relief and reconstruction if floods of the magnitude of 1967 and 1988 are repeated. Unless more concerted efforts are made to prepare for climate hazards, the city will remain vulnerable.

\subsection{Shanghai}

Shanghai ("on the sea" in Chinese) is one of the world's largest seaports and a major industrial and commercial center of the People's Republic of China. It is located at $31^{\circ} 41^{\prime}$ north latitude and $121^{\circ} 29^{\prime}$ east longitude. Bordering on Jiangsu and Zhejiang provinces on the west, Shanghai is washed by the East China Sea on the east and Hangzhou Bay on the south. North of the city, the Yangtze River (or Changjiang) pours into the East China sea. The municipality covers a total area of 6,185 square kilometers, 0.06 percent of China's total territory, which includes the city itself, surrounding suburbs, and an agricultural hinterland. It is also China's most populous urban area with over 16 million inhabitants according to the 2000 Census.

\subsubsection{Physical Environment}

Except for a few hills lying in the southwest corner, most parts of the Shanghai area are flat and belong to the alluvial plain of the Yangtze River Delta. Shanghai's elevation is only 3 to 5 meters above sea level, and averages 4 meters. There are no high mountains in the neighborhood, only the Jiangshuai Plain and the Huabei Plain to the north, and the Eastern China Sea to the east. Cold air masses from the north and moist, warm air from the south meet and mix above Shanghai without topographical hindrance (Zhang and Wang 1998).

Geologically, the Shanghai area lies in the northeast section of the southern Changjiang land mass. Since the beginning of the Quaternary, this area has undergone tectonic subsidence and global marine transgressions and regressions. With the exception of the west, where there are several scattered stripped kops (igneous Mesozoic rocks), most of the area is covered by unconsolidated sediments, including fluvial facies, lacustrine facies, and littoral facies, that range in thickness from 100 to 150 meters in the west to 350 to 400 meters in the east (Xu and Tao 1998).

Since it is located at the mouth of the Yangtze, the Shanghai region is very much the product of riverine and marine processes. The evolution of the landscape has been deeply influenced by local hydrodynamics, especially tidal flows and runoff. A major river, the Yangtze has a yearly 
discharge of $9.24 \times 10^{11}$ cubic meters, and carries an annual sediment load of $4.86 \times 10^{8}$ tons. These sediments feed the delta's continued seaward expansion ( $\mathrm{Xu}$ and Tao 1998). The basin drains a humid region, with average annual precipitation greater than $1000 \mathrm{~mm}$, rising to 2000 $\mathrm{mm}$ in certain localities (Milliman and Mei-e 1995).

The Shanghai area experiences a subtropical monsoon climate. Frequent summer and autumn typhoons bring not only rainstorms that greatly increase surface runoff, but also cause storm surges in coastal areas. Both significantly modify the geomorphic evolution of the coastal area, as illustrated by Typhoon Number 14 that occurred in 1981. This typhoon created high tidal flats, while simultaneously strongly scouring middle and low tidal flats along the local coast. Waves produced by strong northeast river mouth winds also can cause significant coastal erosion, which lowers the surface of the tidal flats and promotes shoreline recession $(\mathrm{Xu}$ and Tao 1998).

\subsubsection{Built Environment}

Shanghai has the Uniform System of classifying Urban Land Use and codes, created by the Construction Ministry, to structure different land uses. Typically, the centers of large cities have high population densities. In the Central Districts of Shanghai, the residential land use occupies 30.06 percent of the area. Among these, good and normal residential quarters (codes R2 and R3) account for 82.4 percent of this residential land, while high quality residential quarters (code R1) and poor quality residential quarters (code R4) represent only 2.72 and 12.6 percent respectively.

\section{Figure 9. Built up area of Shanghai (February 1998)}

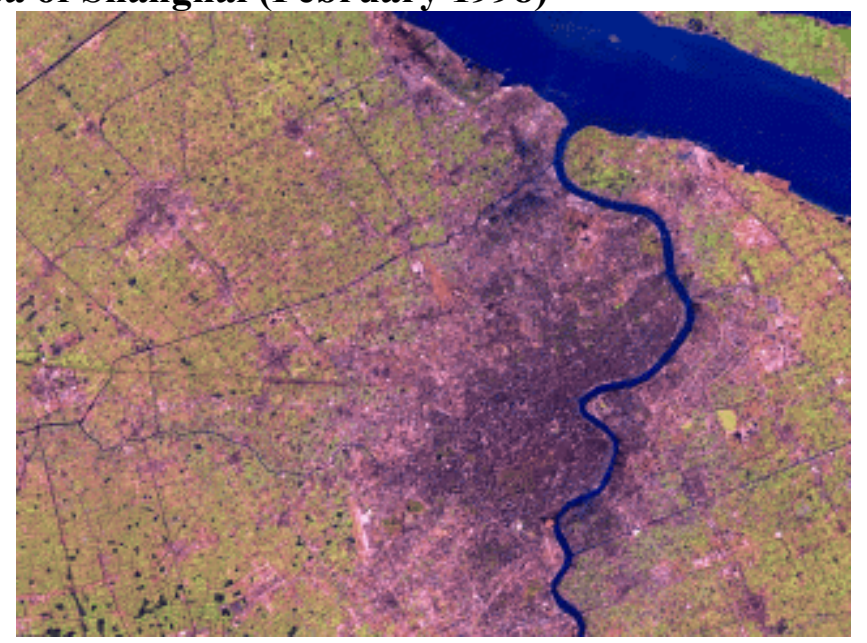

This scene shows the mouth of the Yangtze River in China as seen by the LandSat Thematic Mapper (TM) instrument. The river running northward is the Huangpu River. The city to the west of the Huangpu is Shanghai. Barren and/or recently cultivated land appears red to pink, vegetation appears green, water is dark blue, and artificial structures of concrete and asphalt appear dark grey or black.

Source: NASA, http://svs-f.gsfc.nasa.gov/imagewall/LandSat/shanghai.html

In the central urban area, there are 13.4 square meters of residential land per person, which equates to a housing density of 74,600 persons per square $\mathrm{km}$. The proportion of land devoted to industrial and warehouse use is 22 percent. While lower that that of residential land use, this figure is about 10 percent higher than normally found in developed countries. In contrast, only 8 
percent of the total area is classified as public facility land. Of this, commercial and financial land occupies only 1.2 percent, a full 10 percent lower than typically found in developed countries. The proportion of the land area devoted to squares and roads is 10.15 percent, which amounts to only 4.44 square meters per person. This is one of the reasons for traffic congestion in Shanghai.

To sum up, the structure of Shanghai's land use is not wholly rational. To illustrate, Shanghai's commercial land use area is 10 percent lower than that typically found in cities in developed countries, while that of industrial and warehouse area in the central urban zone is 10 percent higher. As a consequence of the city's low road density, traffic is heavy on narrow roads which have a small traffic carrying capacity and are incapable of adequately handling large numbers of cars. In addition, many small factories, located in the city, have their warehouses in the suburbs, so that each day raw materials must be transported into town, while finished products must be sent to the suburbs. Green areas in the city are limited, reducing opportunities for recreation (Mei, Wu and Zhu 1998).

In terms of use of water resources, the Huangpu River is Shanghai's main source of water. There are over 30 waterworks in Shanghai, of which 11 are located in the urban district along the Huangpu River. Five million tons of tap water are supplied each day to the urban district through a complex network of pipes. Each suburban county also has one or two waterworks. Water resources are used in three significant ways in Shanghai; they are industry, agriculture and public water use with a ratio of $3: 6: 1$. The total volume of water available in Shanghai is about 60 billion cubic meters in a normal year, 54 billion cubic meters in a dry year, and 63.2 billion cubic meters in a wet year marked by floods. Yet even in a dry year, such as 1988, consumption was only 12 billion cubic meters, that is about 19 to 22 percent of the available water. Clearly, as far as quantity is concerned, Shanghai has abundant water resources. However, this does not mean that it is without water related problems. One source reports a sharp rise in stomach cancers in children due to polluted drinking water from river intakes (WWIC 1993).

One of the serious water resources problems is the over-exploitation of groundwater resources, which has caused significant subsidence (Nicholls 1995, Milliman and Mei-e 1995). Since 1921, groundwater has been exploited on a large scale. Because recharge is slow, the water table has fallen and soil moisture has dropped, leading to compression. In the period 1921 to 1965, the mean subsidence in the city of Shanghai was 1.76 meters; the highest recorded figure being 2.63 meters. This process of subsidence encouraged greater intrusion of seawater into Shanghai's waterways, decreasing their quality. Since 1965, the level of groundwater exploitation has been reduced and aquifer recharging projects have been carried out. As a result, subsidence was reduced greatly to as little as a few millimeters annually. However, since 1984, with the development of new industry in suburban counties, the exploitation of groundwater has again increased without adequate control. Levels of recharge have become insufficient and ground subsidence is again increasing rapidly (Zhou and He, 1998). 


\subsubsection{Socioeconomic Conditions}

\section{Endowments}

Shanghai has over 16 million residents in a densely settled downtown area. Shanghai has an average residential density of 74,600 persons per square $\mathrm{km}$. Owing to stringent application of the "one child" family planning policy, in 1993 Shanghai was the first area in China to report a negative natural growth rate (births minus deaths). The city registered a negative population growth rate of -1.9 per thousand in 2000 , based on a birth rate of 5.3 per thousand and mortality rate of 7.2 per thousand. However, rapid rates of in-migration more than make up for declining fertility.

Table 4. Socioeconomic Statistics on Shanghai

\begin{tabular}{|l|l|}
\hline \multicolumn{1}{|c|}{ Indicator } & \multicolumn{1}{c|}{ Value } \\
\hline Metropolitan Area Population & 14.64 million (1998), over 16 million (2000) \\
\hline City Product/capita & $\$ 4,180$ (compared to China GDP of \$3,600 p.c.) \\
\hline Unemployment rate & $3.5 \%$ \\
\hline Mortality rate & 7.2 per 1,000 \\
\hline
\end{tabular}

Sources: Chinese National Bureau of Statistics, http://www.stats.gov.cn/yearbook/1999/d03e.htm (accessed 10/26/01),http://www.sh.gov.cn/gb/shanghai/English/BasicFacts/node184/ (accessed 11/14/01), http://www.photius.com/wfb1999/rankings/gdp per_capita 0.html (accessed 11/14/01), http://www.shanghai.gov.cn/gb/shanghai/english/economy/index.html, (accessed 11/14/01),

\section{Direct Coping}

In August 1998, China experienced devastating floods when the Yangtze overflowed, causing more than 3,000 deaths, affecting 223 million people, displacing 16 million, flooding 25 million hectares of crop land, and causing US\$36 billion in damages (Abramovitz 1999, CIP 1998). Heavy rainfall in 1999 also caused flooding, though less extensive. This put disaster management institutions to the test.

Shanghai has a Municipal Civil Defense Office, which cooperates with the Public Security and Fire Protection agencies. In addition, 284 streets and counties have civil defense organizations, which in turn organize communities into volunteer civil defense teams (China Fire). In August 2001 the Shanghai municipal government organized an international conference on disaster control and emergency services, and invited international and national organizations to participate in order to learn the state-of-the art in terms of disaster management. This, together with a December 2000 training course in Sustainable Urban Development and Disaster Management, indicates a strong interest on the part of the municipality in building its capacity to mitigate and cope with natural disasters.

According to UN Secretary General Kofi Annan (1999), "In China, where extensive disaster control policies have been introduced over the years, the death toll from floods has fallen dramatically. Flooding cost more than 3,000 lives in China in 1998, but similar floods in 1931 and 1954 cost 140,000 and 33,000 respectively. Prevention strategies saved tens of thousands of lives." Among the prevention strategies employed are massive aforestation and reforestation campaigns in the Yangtze river basin to reduce runoff and prevent flooding and landslides 
(Abramovitz 1999). Although US\$2 billion were allocated to reforestation efforts, it is unclear if any money has been allocated to flood defense infrastructure such as dykes.

Although such responses have demonstrated a commitment on the part of national, provincial and municipal authorities to disaster mitigation and preparedness, there are underlying structural impediments to disaster management that are very similar to those found in Mumbai and Rio. These include fragmentation of political authority among central government, provincial and municipal levels, and lack of coordination in the areas of environmental policy (Lieberthal 1997).

\section{Indirect Coping}

Shanghai's population, at 16 million, is largely poor, and is composed of an increasing number of migrants from rural hinterlands. Official statistics do not provide a clear picture of income and wealth distribution, or measures of social cohesion, but a preliminary assessment would suggest that social cohesion is relatively low, though official efforts have been made to involve citizens in disaster response.

Since 1993, Shanghai's natural population growth has reversed from positive to negative, making it the first provincial region in China to experience this phenomenon. Experience in some developed countries suggests that a continuously low, or negative, growth in population generally has one main disadvantage, that is, the shortages in the supply of labor force. However, the introduction of immigrants could partially make up for a deficiency in the indigenous labor force. As of Nov. 2000, 3.8 million migrants reside in the city.

\subsubsection{Likely Future Climate Hazards and Overall Vulnerability Assessment}

Temperature changes for Shanghai suggest that the city will be the most severely affected of the three, with average annual temperature increases of between 2 and $2.5^{\circ} \mathrm{C}$. This will have an impact on evapotranspiration and consequently on the moisture balance. Temperature changes will also likely lead to more severe extra-tropical storms and consequent flooding.

Clearly, the greatest issues of immediate concern for Shanghai are flood defenses in response to subsidence, sea-level rise, and the likelihood that future extreme precipitation will cause flooding from the Yangtze.

\section{Overall Vulnerability}

Like Rio de Janeiro, Shanghai is a city that has been tested by recent and severe flooding. Perhaps given the magnitude of the losses in Shanghai (3,000 dead and 16 million displaced, over against 300 dead in Rio), the government appears to be taking a genuine interest in longterm disaster planning. The municipality has also engaged citizens in "volunteer" civil defense networks, which presumably means that citizens know what to do in the event of disaster and are prepared to take action. 
Figure 10. A schematic diagram of the key converging stresses/perturbations from climate, population, and economy, and the sets of characteristics of Shanghai's socio-ecological system that come together to create vulnerabilities. The dashed arrow suggests a feedback of reinforcing stresses.

\section{Vulnerability of Shanghai To Proiected Climate Change}
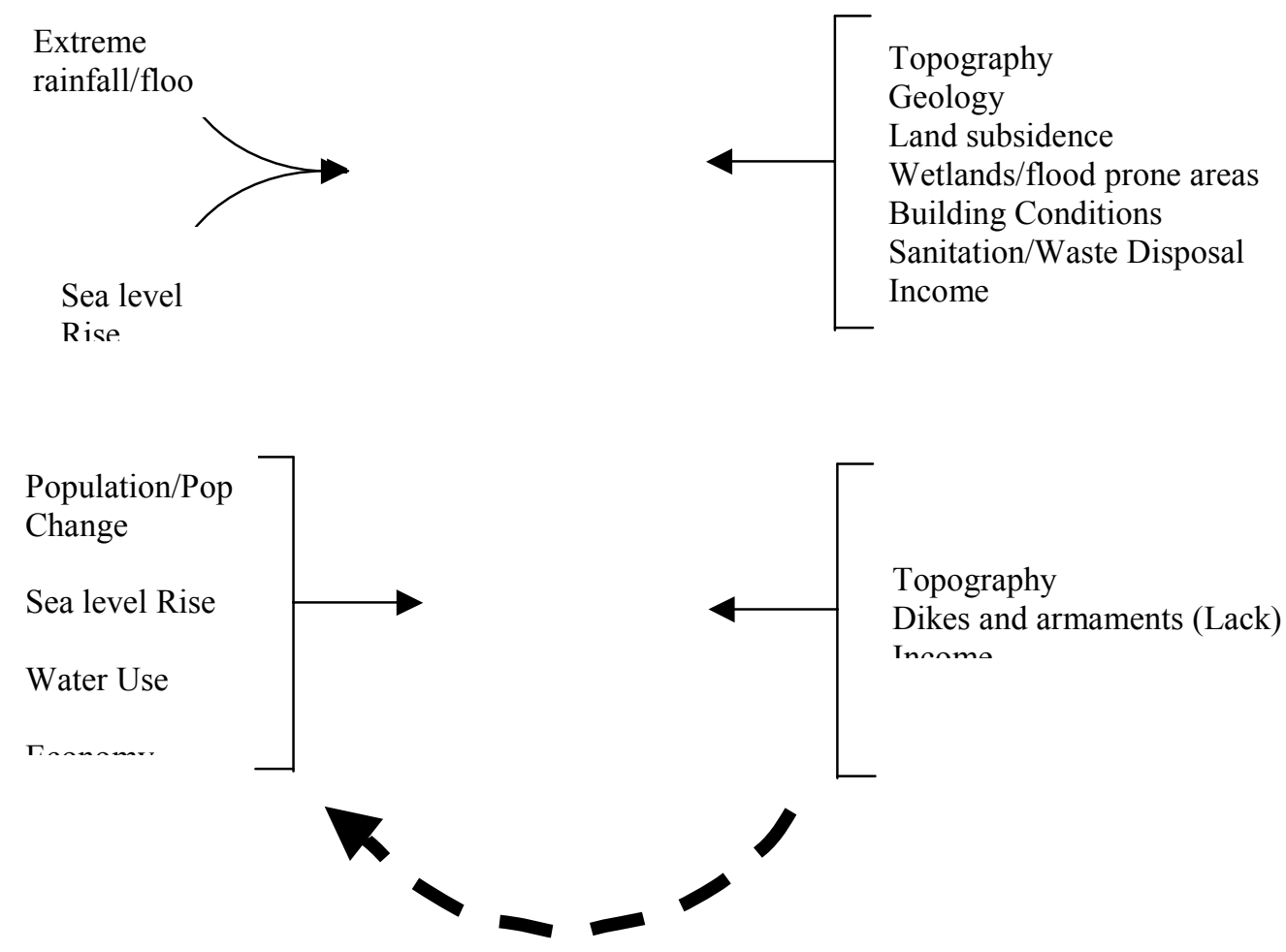

Nonetheless, several key bundles of stress coalesce to create specific vulnerabilities for Shanghai that emerge out of gaps in the city's ability to resist and cope with these stresses. First, sea level rise along with increasing severity and frequency of heavy rains and floods come together with Shanghai's topography (level and low-lying), geology (unconsolidated), land subsidence due to ground water withdrawal, many wetlands and flood-prone areas, the poor condition of many buildings to withstand shifting land and water damage, sanitation and waste disposal systems that are near capacity, and relatively modest income levels. This mix is likely to produce significant vulnerabilities for a large proportion of the city's residents, the city's build infrastructure, and the 
Shanghai region's economy. Second, Shanghai's population is already large and continues to grow rapidly. When this massive trajectory comes together with projected sea level rise and increasing water use by the city, this exacerbates land subsidence, likely puts greater numbers of people in harm's way from climate hazards and coastal erosion, and places people in greater concentration within areas that are likely increasingly flood-prone. This set of circumstances may lead to a diminishing capacity for Shanghai to cope with such stresses because of its burgeoning population on already vulnerable lands, and greater draw-down of ground water causing densely populated lands to subside while sea level continues to rise. This could lead to increases in direct mortality, economic downturn, and potentially even large-scale disease outbreaks.

\section{Discussion and Conclusion}

This paper is first and foremost a preliminary assessment of the value of the extended framework for vulnerability emerging from a broad group of scholars at Clark University, the Stockholm Environment Institute, Stanford University, and Harvard University. Three of the authors on this paper are part of this larger research team involved in developing this extended conceptual framework. Our aim here was not to definitively assess the vulnerability of any of these casestudy cities to climate hazards and change, but instead to use a selection of data to start an examination of the utility and short-comings of the vulnerability framework itself. This is the first time this extended framework for vulnerability has been tested.

We find that new insights about vulnerabilities do emerge from broadening the conceptual frame of vulnerability to consider multiple, synergistic stresses and perturbations on one side of the equation, and multiple, interacting physical and social characteristics of the exposed humanenvironment system on the other side. Vulnerabilities that may have been hidden with simple "summations" of stresses when compared with "summations" of vulnerabilities, were instead illuminated with this process. Further, comparing particular coalescing "bundles of stress" and how they relate to sets of intersecting social and ecological conditions of the exposed system that could serve to heighten or dampen system vulnerability, turned out to be a highly valuable way to uncover gaps in the exposed system's ability to resist, cope with, or respond to specific sets of stresses visited on the system. In fact, we found this approach the most profitable.

This "gap" procedure is actually an approach that emerged through our attempts to practically apply the framework, and is not an obvious feature of the new framework. Due to the extended framework's "total system" approach, we found that such gaps that may exist were indeed hidden rather than made clear by the new framework. At a critical juncture in our attempt to apply the framework, we had to back away from the framework's structure and think through individual lines of stress bundles, and how they relate to sub-sets of socio-physical aspects of the exposed city that would make the city more or less vulnerable to that set of stresses. This was done with a two-column approach - stresses and perturbations on one side, and built, ecological, and social characteristics of the system on the other side. Having to do this made us see the extended framework as an umbrella of what needs to be considered for a nuanced assessment of vulnerability, and how vulnerability arises as a product of system character and stresses, nested in a multiple-scale context, and with dynamic system coping abilities. But, it also made us think 
that such interim steps where needed - where such data breakouts would be necessary to expose details and relationships within the system, or the framework would hide rather than uncover the most critical interactions that could create vulnerability in a particular system. This also highlights the need for descriptive analysis and scenario building as a key part of vulnerability assessment, not only data collection and study. In fact, we found the development of information "stories" presented for each of the case study cities not just descriptive, but analytically useful.

We also found some parts of the extended framework currently beyond our ability to gather appropriate data. This was particularly true when we tried to identify data on informal coping abilities for Shanghai. Informal coping as we defined it relies on surrogate measures of social cohesion, cooperation, and social safety net. Such data, even though they are surrogate measures for such characteristics, were impossible to collect for Shanghai, and difficult to collect for Mumbai and for Rio de Janeiro. While the extended framework includes much richness, it simultaneously begs for better data for the framework to be used to its potential.

We had difficulty addressing the issue of the sequence of stresses and perturbations, to derive useful insights about vulnerability. While the extended framework correctly calls for an acknowledgement of the importance of the sequencing of stresses and perturbations - not just what they are and their magnitude - we were unable to test this issue during the current study.

Finally, we found very useful that the extended framework for vulnerability formally codified the concept of dynamically adjusting system coping and response abilities, and system feedbacks. This was a very powerful addition to current vulnerability conceptualizations. Adding dynamic system feedbacks allowed us to identify links that could either dampen impacts or increase them, as shown schematically with the dashed arrows in Figures 6, 8, and 10.

Our efforts reported here are a partial and preliminary exploration of the usefulness of the extended vulnerability framework. Our early findings suggest that it does bring forth new insights and helps drive improved vulnerability analysis. Descriptive scenarios of subcomponents of the larger system were found to be a critical component for making greatest insights into vulnerability creation, and what areas may be most profitable for trying to disconnect the chains of causation that create vulnerabilities, risks, and harm. Learning what combination of issues and system characteristics create vulnerabilities is only one part of a broader issue about how to reduce vulnerability, in this case for climate hazards and climate change.

From a policy perspective, there are few easy prescriptions for how to reduce vulnerability and better prepare for future climate hazards, at least in the case of the developing country cities we describe above. Among other things, this may be attributed to the following factors (Di John 2001):

- Disasters are an unequally distributed public "bad" that is more likely to affect poorer, more vulnerable sub-populations with the least political influence. Mitigation measures, by contrast, are a public good that require substantial investment and adequately functioning institutions. 
- Low tax collection capacity and low income constrains the resources available to the government to make necessary infrastructural or institutional investments. Government resources themselves may become highly contested through political maneuvering (as in the case of Brazil).

- The wealthy and more influential classes may simply choose to "exit" from political decision-making processes, rather than voice their concern over the lack of disaster preparedness. Exit means that they opt out of public resources, and choose to invest instead in their own capability set (e.g., purchasing a well-built home in a safe location, insurance policies, or private education and health care).

- If vulnerability mitigation/prevention measures are expensive, there may exist a "moral hazard" on the part of state decision-makers since they may assume that the international relief community will come to their assistance in the event of a significant natural disaster. Thus, to act means committing scarce public resources for a medium or even low probability future event, whereas to "wait and see" if disaster strikes, and later to claim that the disaster could not be foreseen, shifts the financial burden onto international agencies.

The authors do not underestimate in any way the difficulties entailed in preparing adequately for future climate change-related vulnerabilities, no matter what kind of framework used. Given these political and institutional issues, it is worth considering how communities themselves, through micro-planning or other efforts at collective organization might develop plans and infrastructure necessary to reduce their vulnerability to natural disasters in contexts in which governments either lack the resources or are unwilling to consider investments in preparedness (Goethert 1988). Many efforts to improve local environments, such as enhanced drainage and improved waste disposal, also reduce vulnerabilities to disasters and their consequences (such as the spread of disease).

\section{Acknowledgements}

This paper is based on research supported (in part) by a grant from the National Science Foundation (award BCS-0004236) with contributions from the National Oceanic and Atmospheric Administration's Office of Global Programs for the Research and Assessment Systems for Sustainability Program. The authors would like to acknowledge the kind assistance of Richard Goldberg of NASA's Goddard Institute of Space Studies (GISS) in helping to provide and interpret climate change scenario information for the three cities, and of Kristine $(\mathrm{Ke}) \mathrm{Xu}$, graduate student in Environmental Studies and Journalism at Columbia University, for providing research support on the Shanghai case study. Diana Liverman of the University of Arizona also provided useful comments during the Open Meeting session in which this paper was presented. 


\section{References}

Abramovitz, J. (1999). "Natural Disasters: At the Hand of God or Man?" Environmental News Network, 23 June 1999, accessed at http://www.enn.com/enn-features-archive/1999/06/062399/disaster_3932.asp on 29 October 2001.

Allen, E. (1994). "Political Responses to Flood Disaster: The Example of Rio de Janeiro," in Disasters, Development and Environment, Ann Varley (ed.), New York: John Wiley \& Sons, Ltd.

Annan, K. (1999). “An Increasing Vulnerability to Natural Disasters," International Herald Tribune, 10 September 1999, accessed at http://www.un.org/Overview/SG/annan press.htm on 29 October 2001.

Baptista de Araújo, S. (1994). "Rio de Janeiro and Natural Disasters," STOP Disasters, No. 21, Sept-Oct 1994.

Bird, Eric C.F. (1995). "Present and Future Sea Level: The Effects of Predicted Global Changes," in Climate Change Impact on Coastal Habitation, Doeke Eisma (ed.). Boca Raton, FL: Lewis Publishers.

Bizzarro, D. (2001). "New CEI Center Will Use Scientific Advances to Protect Societies Facing Disaster," Columbia Earth Institute news release, accessed 25 Sept 2001 at http://www.earthinstitute.columbia.edu/news/story6 2 01.html.

Bogard, W. C. (1989). "Bringing Social Theory to Hazards Research: Conditions and Consequences of The Mitigation of Environmental Hazards." Sociological Perspectives 31: 147-68.

Bombay First (2001). Accessed on-line at http://www.bombayfirst.org/g-statistics.htm, 30 July 2001.

Brockerhoff, M. (2000). “An Urbanizing World,” Population Bulletin, Vol. 55, No. 3, September 2000.

CIA (Central Intelligence Agency) (2001). World Fact Book, Washington, DC: Government Printing Office.

Chambers, R. (1989). "Vulnerability, coping and policy." IDS Bulletin 20: 1-7.

China Fire. "New Disaster Assistance Management Help Residents Away from Misadventure," accessed at http://eng.china-fire.com/news/domestic/New\%20Disaster\%20Assistance\%20Management.htm on 30 October 2001.

CIP (Climate Information Project) (1998). Reports accessed at http://www.cip.ogp.noaa.gov/ on 30 October 2001.

Collett-White, M. (2001), "Britons Wonder 'Will it Ever Stop Raining?'," Planet Ark News Service, accessed on the web at http://www.planetark.org/dailynewsstory.cfm?newsid=10738 on 25 Sept. 2001.

Corrêa do Lago, L. (1999). "Divisão Sócio-Espacial e Mobilidade Residencial: Reprodução ou Alteração das Fronteiras Espaciais?," Instituto de Pesquisa e Planejamento Urbano e Regional, Universidade Federale do Rio de Janeiro (IPPUR/UFRJ).

Cunha, L. R., and M. Miller Santos (1993). "The Rio Reconstruction Project: The First Two Years," in Towards A Sustainable Urban Environment: The Rio de Janeiro Study, World Bank Discussion Paper 195, Washington, DC: World Bank. 
Cutter, S. L., J. T. Mitchell, , and M. S. Scott. (2000). "Revealing the Vulnerability of People and Places: A Case Study of Georgetown County, South Carolina." Annals of the Associations of American Geographers 90 (4): 713-737.

Deelstra, T. (1995). "Impact of Climatic Change on Coastal Cities," in Climate Change Impact on Coastal Habitation, Doeke Eisma (ed.). Boca Raton, FL: Lewis Publishers.

Demographia (2000). "50 Largest World Metropolitan Areas by Nation," accessed at http://www.demographia.com/db-world-metro2000natl.htm on 3 July 2001.

Di John, J. (2001). “An Institutionalist Political Economy Perspective of Risk and Vulnerability," presentation at a joint World Bank/Columbia University workshop on Assessment of High Risk Disaster Hotspots, Palisades, NY, 6-7 September 2001.

Dow, K. (1992). "Exploring Differences in Our Common Future(s): The Meaning of Vulnerability to Global Environmental Change." Geoforum 23: 417-36

Downie, A.(2001). "Brazilians Hit the Dimmer Switch," Christian Science Monitor, accessed on the web at http://www.csmonitor.com/durable/2001/05/31/p6s1.htm on 6 June 2001.

Downing, T. E. (1991). Vulnerability to Hunger and Coping with Climate Change in Africa. Global Environmental Change 1: 365-80.

Economic Times (2001). January $31^{\text {st }} 2001$ : http://www.economictimes.com/310101/31econ $18 . h t m$

Fernandes, E. (2000). "The Legalisation of Favelas in Brazil: Problems and Prospects," Third World Planning Review, Vol. 22, No. 2: 167-188.

Gabor, T. and T. K. Griffith. (1980). "The Assessment of Community Vulnerability to Acute Hazardous Materials Incidents.” Journal of Hazardous Materials 8: 323-33.

Geddes, B., and A. R. Neto (1992). "Institutional Sources of Corruption in Brazil," Third World Quarterly, Vol. 13, No. 4: 641-661.

Geocities (2000). "Mumbai Urban Transport Project," Accessed at http://www.geocities.com/mutprail/ on 3 July 2001.

Goethert, R. and N. Hamdi (1988), Making Microplans. A Community-based Process in Design and Development, Intermediate Technology Publications, London.

Guo, H. "Causes and the Performance of the Construction Work for Flood Tide Prevention in Shanghai." In: Frasetto, R. (ed.), Impact of Sea Level Rise on Cities and Regions. Proceedings of the First International Meeting 'Cities on Water', Venice, December 1989. pp. 150-156. Marsillio Editori, Venice 1991.

Haq and Haq (1998). Cited in Sharma 2000: 88.

Hutchinson Family Encyclopedia (2000). "Mumbai," accessed at http://ebooks.whsmithonline.co.uk/htmldata/ency.asp?mainpage=HTTP://EBOOKS.WHSMITHONLINE .CO.UK/ENCYCLOPEDIA/85/M0018085.HTM on 3 July 2001. 
Indian Express (2000). "Toll in Landslide Rises to 61," India Express, July 14, 2000, accessed at http://www.expressindia.com/ie/daily/20000714/ina14066.html on 3 July 2001.

Instituto Brasileiro de Geografia e Estatistica (IBGE) web site, http://www1.ibge.gov.br/ibge/default.php, accessed on 3 September 2001.

IPCC (2001). Climate Change 2001: Impacts, Adaptation, and Vulnerability, Summary for Policymakers and Technical Summary of the Working Group II Report of the Intergovernmental Panel on Climate Change Third Assessment, 2001.

Kates, R. W., W.C. Clark, R. Corell, J.M. Hall, C.C. Jaeger, I. Lowe, J.J. McCarthy, H.J. Schellnhuber, B. Bolin, N.M. Dickson, S. Faucheux, G.C. Gallopin, A. Gruebler, B. Huntley, J. Jäger, N.S. Jodha, R.E. Kasperson, A. Mabogunje, P. Matson, H. Mooney, B. Moore III, T. O'Riordan, and U. Svedin. 2001. "Sustainability science." Science 292:641-42.

Kreimer, A., T. Lobo, B. Menezes, M. Munasinghe, R. Parker, and M. Preece (1993). "Rio de Janeiro In search of Sustainability," in Towards A Sustainable Urban Environment: The Rio de Janeiro Study, World Bank Discussion Paper 195, Washington, DC: World Bank.

Lieberthal, Kenneth (1997). "China's Governing System and Its Impact on Environmental Policy Implementation," China Environment Series 1, Fall 1997, Washington, DC: Woodrow Wilson International Center for Scholars.

Liverman, D. (1990). "Vulnerability to Global Environmental Change." In Understanding Global Environmental Change: the Contributions of Risk Analysis and management, edited by R.E. Kasperson et al. Worcester, MA: Clark University, The Earth Transformed Program, 27-44.

Maimon, D. (2001). President, Association for Support and Incentives to Environmental Management (SIGA). Personal communication, 22 August 2001.

MIUL (Megacities Innovations for Urban Life) (2001). "Mumbai, India," Accessed at http://www.megacities.org/network/mumbai.asp on 23 June 2001.

Mei, A., J. Wu. And L. Zhu (1998). "Shanghai's Land Use”, in The Dragon's Head: Shanghai, China's Emerging Megacity, edited by Harold D. Foster, David Chuenyan Lai, Naisheng Zhou.

Milliman, J. D., and R. Mei-e (1995). "River Flux to the Sea: Impact of Human Intervention on River Systems and Adjacent Coastal Areas," in Climate Change Impact on Coastal Habitation, Doeke Eisma (ed.). Boca Raton, FL: Lewis Publishers.

Mitchell, J.K. (1989). "Hazards research.” In Geography in America, edited by Gaile, G.L., and C.J. Willmott. Columbus, OH: Merrill.

MMRDA Planning. Accessed at http://www.mmrdamumbai.org/planning.htm on 23 June 2001.

MMRDA Backbay. Accessed at http://www.mmrdamumbai.org/backbay.htm on 23 June 2001.

MMRDA Bandra-Kurla. Accessed at http://www.mmrdamumbai.org/bandkurl.htm on 23 June 2001. 
Muehe, Dietre (2001). Professor, Department of Geography, Federal University of Rio de Janeiro.

Personal communication, 22 August 2001.

Mumbai Pages (1999). "MMRDA Masterplan," Accessed at

http://theory.tifr.res.in/bombay/amenities/housing/masterplan.html on 23 June 2001.

Mumbai Pages (1999). "History," Accessed at http://theory.tifr.res.in/bombay/history/ on 24 June 2001.

Mumbainet (2001). "Temperatures in Mumbai," Accessed at

http://www.mumbainet.com/cityinfo/temperature.htm on 24 June 2001.

NOAA/OGP (National Oceanographic and Atmospheric Administration/Office of Global Programs) (1999). National Oceanographic and Atmospheric Administration, Office of Global Programs Climate Information Project archives, 13 June 2001, accessed at

http://www.cip.ogp.noaa.gov/Library/weeklyus/2001/us06.13.01.html, visited 25 Sept. 2001.

NOAA/OGP (National Oceanographic and Atmospheric Administration/Office of Global Programs) (1999). National Oceanographic and Atmospheric Administration, Office of Global Programs Climate Information Project archives, 27 December 1999, accessed online at http://www.cip.ogp.noaa.gov/Library/weekly/1999/12.27.99.html on 24 Sept 2001.

Nicholls, R. (1995). “Coastal Megacities and Climate Change,” GeoJournal, Vol. 37, No. 3, pp. 369-379.

NRC (National Research Council) (1999). Our Common Journey: A Transition Toward Sustainability. Board on Sustainable Development, Policy Division, National Research Council. Washington D.C.: National Academy Press.

The Observer of India (2001). "BMC to inspect buildings for damages during quake," The Sunday Observer, January 29, 2001 issue, accessed at

http://www.observerindia.com/news/200101/29/POLstates02.htm on 23 June 2001.

Rayner, S., and E. L. Malone (1997). "Zen and the Art of Climate Maintenance," Nature, Vol. 390, November 27, 1997.

Rosenzweig, C., and W. D. Solecki (2001). "Climate Change and a Global City," in Environment, Vol. 43, No. 3, April 2001, pp. 8-18.

Schnack, E.J. (1993). "The Vulnerability of the East Coast of South America to Sea Level Rise and Possible Adjustment Strategies," in Climate and Sea Level Change: Observations, Projections and Implications, R.A. Warrick, E.M. Barrow, and T.M.L. Wigley (eds.), Cambridge, UK: Cambridge University Press.

Sharma, V. K. (2000). "Problems of Marine Ecosystems And Sustainability of Coastal Cities: A Focus on Mumbai, India." Indian Journal of Environmental Health, Vol. 42, No. 2, pp. 82-91.

SPARC (Society for the Promotion of Area Resource Centres) (2001). "SPARC and its work with the National Slum Dwellers Federation", accessed on-line at http://www.sparcindia.org/documents/alliance.html on 23 June 2001.

Susman, P., P. O’Keefe, and B. Wisner (1984). "Global disasters: a radical interpretation.” In Interpretations of Calamity, edited by Hewitt, K. Boston: Allen \& Unwin, pp. 264-83. 
TERI (Tata Energy Research Institute) (1996). The Economic Impact of a One Metre Sea Level Rise on the Indian Coastline: Method and Case Studies. Report submitted to the Ford Foundation.

The Times of India (2001). Accessed at http://www.indiatimes.com/news/220601toi/22mbom1.htm on 22 June 2001.

Timmerman, P. (1981). "Vulnerability, resilience and the collapse of society: a review of models and possible climatic applications." Institute for Environmental Studies, Environmental Monograph No. 1. Toronto: University of Toronto.

UNDRO (United Nations Disaster Relief Organization) (1982). Natural disasters and vulnerability analysis. Geneva: Office of the United Nations Disaster Relief

Coordinator.

UNDP (United Nations Development Program) (2001). Press Release, accessed online at http://www.undp.org.in/NEWS/PRESS/press138.htm on 23 June 2001.

Wang, B., S. Chen, K. Zhang and J. Shen (1995). "Potential Impacts of Sea-Level Rise on the Shanghai Area." Journal of Coastal Research, Special Issue 14, pp.151-166.

Watts, M.J., and J.G. Bohle. (1993). "The space of vulnerability: the causal structure of hunger and famine." Progress in Human Geography. 17:43-67.

World Bank and Center for Hazards and Risk Research at Columbia University (2001). Assessment of High-Risk Disaster Hotspots, A joint World Bank/Columbia University workshop, Lamont-Doherty Earth Observatory, Palisades, NY, 6-7 September 2001.

World Bank (1996). "From Rationing to Full Service: Water and Sanitation Challenge for Bombay," accessed on-line at

http://wbln0018.worldbank.org/oed/oeddoclib.nsf/View+to+Link+WebPages/9A7152C54E38F2EE85256 7F5005D8DD5?OpenDocument on 30 July 2001.

WWIC (Woodrow Wilson International Center) (1998), China Environment Series 2, Woodrow Wilson International Center for Scholars Environmental Change and Security Project, Summer 1998.

Xu, S. and J. Tao (1998). “The Geomorphology of Shanghai”, in The Dragon's Head: Shanghai, China's Emerging Megacity, edited by Harold D. Foster, David Chuenyan Lai, Naisheng Zhou.

Zhang, C. and Y. Wang (1998). “The Climate of Shanghai”, in The Dragon's Head: Shanghai, China's Emerging Megacity, edited by Harold D. Foster, David Chuenyan Lai, Naisheng Zhou.

Zhou N. and B. He (1998). "Hydrology and Water Resources", in The Dragon's Head: Shanghai, China's Emerging Megacity, edited by Harold D. Foster, David Chuenyan Lai, Naisheng Zhou. 